\title{
Regional climate model assessment of the urban land-surface forcing over central Europe
}

\author{
P. Huszar ${ }^{1}$, T. Halenka ${ }^{1}$, M. Belda ${ }^{1}$, M. Zak ${ }^{1}$, K. Sindelarova ${ }^{1, *}$, and J. Miksovsky ${ }^{1}$ \\ ${ }^{1}$ Department of Meteorology and Environment Protection, Faculty of Mathematics and Physics, Charles University, Prague, \\ V Holešovičkách 2, Prague 8, 18000, Czech Republic \\ * now at: UPMC Univ. Paris 06; Université Versailles St-Quentin; CNRS/INSU; LATMOS-IPSL, Paris, France
}

Correspondence to: P. Huszar (peter.huszar@mff.cuni.cz)

Received: 19 May 2014 - Published in Atmos. Chem. Phys. Discuss.: 14 July 2014

Revised: 15 September 2014 - Accepted: 21 October 2014 - Published: 26 November 2014

\begin{abstract}
For the purpose of qualifying and quantifying the climate impact of cities and urban surfaces in general on climate of central Europe, the surface parameterization in regional climate model RegCM4 has been extended with the Single-layer Urban Canopy Model (SLUCM). A set of experiments was performed over the period of 2005-2009 for central Europe, either without considering urban surfaces or with the SLUCM treatment. Results show a statistically significant impact of urbanized surfaces on temperature (up to $1.5 \mathrm{~K}$ increase in summer) as well as on the boundary layer height (increases up to $50 \mathrm{~m}$ ). Urbanization further influences surface wind with a winter decrease up to $-0.6 \mathrm{~m} \mathrm{~s}^{-1}$, though both increases and decreases were detected in summer depending on the location relative to the cities and daytime (changes up to $0.3 \mathrm{~m} \mathrm{~s}^{-1}$ ). Urban surfaces significantly reduce the humidity over the surface. This impacts the simulated summer precipitation rate, showing a decrease over cities of up to $-2 \mathrm{~mm}$ day $^{-1}$. Significant temperature increases are simulated over higher altitudes as well, not only within the urban canopy layer. With the urban parameterization, the climate model better describes the diurnal temperature variation, reducing the cold afternoon and evening bias of RegCM4.

Sensitivity experiments were carried out to quantify the response of the meteorological conditions to changes in the parameters specific to the urban environment, such as street width, building height, albedo of the roofs and anthropogenic heat release. The results proved to be rather robust and the choice of the key SLUCM parameters impacts them only slightly (mainly temperature, boundary layer height and wind velocity).
\end{abstract}

Statistically significant impacts are modelled not only over large urbanized areas, but the influence of the cities is also evident over rural areas without major urban surfaces. It is shown that this is the result of the combined effect of the distant influence of the cities and the influence of the minor local urban surface coverage.

\section{Introduction}

The artificial urban surfaces are clearly distinguished from natural surfaces by mechanical, radiative, thermal and hydraulic properties. Therefore, these surfaces represent additional sinks and sources of momentum, heat and moisture affecting the mechanical, thermodynamical, and hydrological properties of local atmosphere and have specific impact on the meteorological conditions (Oke, 1982, 1987; Godowitch et al., 1985; Eliasson and Holmer, 1990; Haeger-Eugensson and Holmer, 1999).

One of the most comprehensively studied aspects of the meteorological impact of urban surfaces is the urban heat island (UHI) phenomenon, which represents an excess warmth of urbanized areas with respect to their non-urbanized (rural) vicinity. In general, UHI forms due to significant perturbation of fluxes of energy, moisture and momentum within this environment, which is characterized by canyon-like geometry and specific thermal parameters of the artificial surfaces (Oke, 1982). Due to their decreased albedo, urban surfaces store more heat compared to rural areas and after sunset this heat is released with a reduced efficiency because of the decreased sky-view factor (Grimmond and Oke, 1995) mak- 
ing UHI typical for night-time, although it is detectable during daytime as well. The UHI is enhanced by several other factors. Increased anthropogenic heat emission within urban environment increases urban temperatures (Block et al., 2004). Further, urban areas covered by impervious surfaces exhibit higher runoff than their rural counterparts, which leaves them with less surface water available for evaporation. Lower evaporation decreases the latent heat consumption causing the perturbation of energy balance, which leads to temperature increase (Grimmond and Oke, 1991; Taha, 1997).

Some studies performing site measurement in and around cities revealed the so-called urban cool island (UCI) effect as well: during the morning hours, the enhanced shadowing within urban surfaces delays the heating and causes lower temperatures than over the rural surfaces (Basara et al., 2008; Gaffin et al., 2008).

Urban surfaces have further impacts on other meteorological parameters as well: Richards and Oke (2002) and Richards (2004) studied the changes of surface humidity, while Grimmond and Oke (2002), Roth (2000) or KastnerKlein et al. (2001) focused on the impact on roughness and turbulence. Many studies dealt with the structure of the urban boundary layer including the impact on the height of the planetary boundary layer (ZPBL) (Piringer, 2001; Cleugh and Grimmond, 2001; Martilli, 2002; Angevine et al., 2003; Nair et al., 2004) and wind speed (Hou et al., 2013). Urbanization-triggered changes in precipitation and hydrological processes also got the attention of research studies (Dettwiller and Changon, 1976; Shepherd et al., 2002; Rozoff et al., 2003). There is evidence that the urban environment with its higher air pollution is responsible for enhanced lightning (Farias et al., 2009; Coquillat et al., 2013). Schaldach and Alcamo (2007) showed significant influence on the carbon balance as well and, finally, the urban-meteorology interaction may significantly influence air quality (Rigby and Toumi, 2008; Ryu et al., 2013a, b). However, most of the influences listed here have to be viewed in a common UHIrelated framework as they are all physically connected within this phenomenon, bringing higher street level temperatures and having a direct impact on human health (Reid et al., 2009) and, in general, on the comfort of living.

Numerous studies aimed to find observational (surface measurements, reanalysis or satellite based) evidence for the UHI in different parts of the Earth in the past (e.g. Eliasson and Holmer, 1990; Basara et al., 2008; Svoma and Brazel, 2010; Yang et al., 2011; Zhou and Reng, 2011; Giannaros and Melas, 2012; Pichierri et al., 2012). To provide a reliable, numerical modelling based perspective of the UHI phenomenon, and of other related impacts (e.g. on wind speed/direction, precipitation, ZPBL), the complex nature of the mechanical, thermodynamical and radiative processes have to be realistically represented in models. Current operational numerical weather prediction models as well as regional climate models still fail to capture properly the impact of local urban features on the mesoscale meteorology and climate, despite their increasing resolution. Therefore the inclusion of urban canopy models (UCMs), which are specially designed to parameterize the processes specific to the urban environment that are not resolvable at the model's scale, is necessary (Baklanov et al., 2008; Lee and Park, 2008; Oleson et al., 2008; Chen et al., 2011).

Along with the development of UCMs, many modelling studies were carried out to describe UHI and other aspects of the urban-atmosphere interaction. Most of the studies focused on a particular city with minor interest in the impact on regional scale further from the urban area itself. Examples of such recent modelling studies include the following: Klaić et al. (2002) for Zagreb, Croatia; Flagg and Taylor (2011) for Detroit-Windsor, USA; Giannaros et al. (2013) for Athens, Greece; Wouters et al. (2013) for Paris, France; Miao et al. (2009) and Hou et al. (2013) for the Beijing area, China. These studies conducted experiments for time periods of several days during selected weather episodes only. Furthermore, as mentioned earlier, they focused on the scales of at most a few tens of kilometres around a particular city. Recently, Zhang et al. (2009), Wang et al. (2012) and Feng et al. (2013) examined the impact of urban land surfaces on the regional climate but with focus on eastern Asia. Over Europe, Struzewska and Kaminski (2012) examined the regional impact of urban surfaces on the forecast of local and regional meteorological conditions and selected pollutants. However, they were not interested in the long-term impacts and performed simulations of only a few tens of hours for three selected episodes. Block et al. (2004) carried out experiments on a regional scale over central Europe as well, but they were interested in the impact of the anthropogenic heat release (AHR) only, without any attention to other aspects of urban climate interactions (e.g. radiation-induced UHI phenomenon).

The study performed by Trusilova et al. (2008) over Europe used model MM5 to examine the impact of urban surfaces on climate in the months of July and January over 5 consecutive years. They used a single-layer parameterization with simplified urban geometry representation (TEB - Town Energy Budget model; Masson, 2000).

The present study is one of the first that aims to examine the regional and long-term impact of all urban surfaces on the regional climate of central Europe. To achieve this goal, the regional climate model RegCM4.2 was coupled with the Single-layer Urban Canopy Model (SLUCM) that accounts for the most relevant processes specific to the urban environment including the AHR. The climate impact of urbanization for day and night-time conditions is examined separately, for winter and summer months. The results are evaluated against surface measurements as well. A few sensitivity experiments are carried out to examine the results based on the setting of the key parameters of the SLUCM and on different resolutions of the surface model. Finally, it is shown how a partic- 
ular city (Prague) influences the region by disregarding all urban surfaces except those within this city.

\section{Tools and experimental set-up}

\subsection{The regional climate model RegCM4.2}

The regional climate model used in this study is the model RegCM version 4.2 (hereafter referred to as RegCM4.2), a 3$\mathrm{D}$ mesoscale model developed at The International Centre for Theoretical Physics (ICTP) and is described in full by Giorgi et al. (2012). Its dynamical core is based on the hydrostatic version of the NCAR-PSU Mesoscale Model version 5 (MM5) (Grell et al., 1994). The radiation is solved using the Community Climate Model version 3 (CCM3) parameterization (Kiehl et al., 1996). The large-scale precipitation and cloud processes are calculated following Pal et al. (2000) and the convection is parameterized with either the the Grell scheme (Grell, 1993), Kuo scheme (Anthes, 1977) or the MIT-Emanuel scheme (Emanuel and ZivkovicRothman, 1999). The planetary boundary layer scheme is based on Holstag et al. (1990).

RegCM4.2 includes two land surface models: Biosphere-Atmosphere Transfer Scheme (BATS), originally developed by Dickinson et al. (1993); and the Community Land Surface Model v3.5 (CLM3.5) (Oleson et al., 2008; Tawfik and Steiner, 2011) as an optional land surface parameterization.

The BATS scheme is designed to describe the role of vegetation and interactive soil moisture in modifying the surface-atmosphere exchanges of momentum, energy, and water vapour. It considers a vegetation layer, a snow layer, a surface soil layer $(10 \mathrm{~cm}$ thick) or root zone layer (1-2 m thick) and a deep soil layer ( $3 \mathrm{~m}$ thick). Soil layer temperatures are calculated using a generalization of the force-restore method of Deardoff (1978). The energy balance formulation (including sensible, radiative, and latent heat fluxes) is used for computing temperature of the canopy and canopy foliage.

The soil hydrology calculations include predictive equations for the water content of the soil layers, accounting for precipitation, snowmelt, canopy foliage drip, evapotranspiration, surface runoff, infiltration below the root zone, and diffusive exchange of water between soil layers. Surface runoff rates are expressed as functions of the precipitation and soil water saturation. Snow depth is prognostically calculated from snowfall, snowmelt, and sublimation. It is assumed that precipitation falls in the form of snow if the temperature of the lowest model level is below $271 \mathrm{~K}$.

Sensible heat, water vapour, and momentum fluxes at the surface are calculated using a standard surface drag coefficient formulation based on surface-layer similarity theory. The drag coefficient depends on the surface roughness length and on the atmospheric stability in the surface layer. The surface evapotranspiration rates depend on the availability of soil water. Within BATS, 20 vegetation types are distinguished.

An improvement in describing the land surface fluxes within the BATS scheme can be achieved by a sub-grid land surface configuration by which each model grid point is divided into a regular sub-grid, and land surface processes are calculated at each sub-grid point taking into account the local land use and topography (Giorgi et al., 2003).

To describe urbanized surfaces, two new land use types were added to BATS with the introduction of RegCM version 4.0 and higher. These new land use types alter the values of albedo, roughness length, soil characteristics, and maximum vegetation cover in order to account for the modified surface energy balance (heat and momentum), evapotranspiration and runoff specific to urbanized surfaces (parameters are taken from Kueppers et al., 2008). This represents a bulk parameterization of zero-order effects of urban and suburban land use types, which however ignores the 3-D character of the processes that occur in the urban environment (e.g. in street-canyons). Therefore, we implemented a more sophisticated treatment of the meteorological processes that occur in connection with urban surfaces. Chen et al. (2011) provided an overview of the urban parameterizations that are implemented in the Weather Research and Forecasting model (WRF; Skamarock et al., 2008). For our study, the Singlelayer Urban Canopy Model (SLUCM) is used. It is less complex compared to the multi-layer urban canopy models (MLUCMs) and therefore computationally less demanding in long term climate model simulations. On the other hand, it accounts for the 3-D meteorological processes occurring in the cities' environment, such as trapping the radiation within the street-canyon and shadowing due to buildings. The following section gives a more detailed description of SLUCM.

\subsection{The Single-layer Urban Canopy Model}

The Single-layer Urban Canopy Model was developed by Kusaka et al. (2001) and Kusaka and Kimura (2004). It represents the geometry of cities assuming infinitely long street canyons, where it considers shadowing, reflections, and trapping of radiation and prescribes an exponential wind profile (Fig. 1). The model calculates the surface skin temperatures of the roof, wall, and road (determined from the surface energy budget) and temperature profiles within roof, wall, and road layers (determined from the thermal conduction equation) as prognostic variables. Surface-sensible heat fluxes from each surface are calculated using Monin-Obukhov similarity theory and the Jurges formula, which is widely used in the field of architecture (e.g. Tanaka et al., 1993). SLUCM calculates canyon drag coefficient and friction velocity using a similarity stability function for momentum. For a detailed description of the SLUCM, please refer to Kusaka et al. (2001).

The implementation of SLUCM into RegCM4.2 follows the way of its coupling to the WRF model (Chen et al., 2011). 


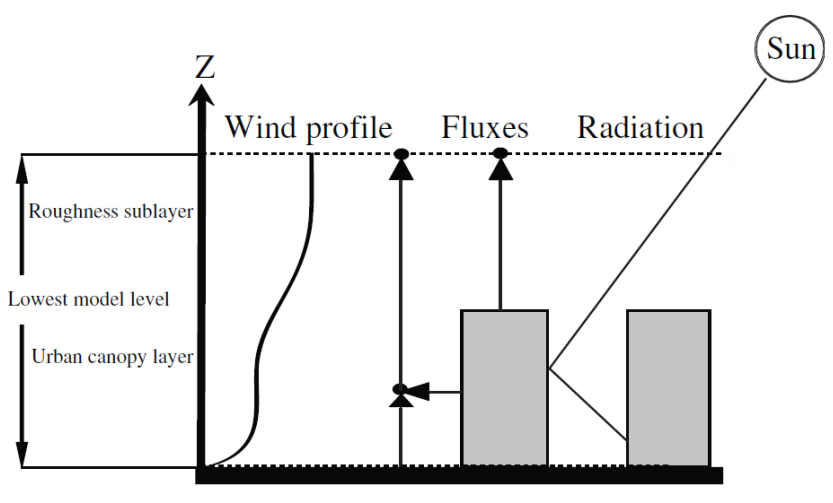

Figure 1. A schematic representation of the SLUCM (after Chen et al., 2011).

SLUCM is coupled to the RegCM4.2 within the BATS surface model, eventually using the BATS's subgrid treatment (SUBBATS). Whenever BATS finds a subgrid box covered by urban surface in the subgrid land use file, it calls SLUCM routines. The total sensible heat flux from roofs, walls, roads, and the urban canyons is then passed to the RegCM4.2's BATS model. The total momentum flux is passed back in a similar way. BATS then calculates the overall flux for the model grid box by aggregating the fluxes from non-urban and urban surfaces provided by SLUCM. Similarly, the total friction velocity is aggregated from urban and non-urban surfaces and passed to RegCM4.2 boundary-layer scheme. The anthropogenic heat release (AHR) and its diurnal variation are considered and added to the sensible heat flux from the urban canopy layer.

\subsection{Model configuration and experiments performed}

Several experiments are performed using the RegCM4.2/SLUCM model over $10 \mathrm{~km} \times 10 \mathrm{~km}$ resolution domain of $158 \times 118$ grid points covering central Europe. The initial and lateral boundary conditions for RegCM4.2 were taken from the ERA-Interim data (Simmons et al., 2007). The convection was parameterized with the Grell scheme with the closure assumption of Fritsch and Chappell (1980). The BATS scheme was configured with a $2 \mathrm{~km} \times 2 \mathrm{~km}$ subgrid set-up, which provides the opportunity to resolve and to describe medium and large continuous urban surfaces (cities) over the targeted area. A further increase of the subgrid division would definitely be beneficial, but it comes with a significant reduction of model speed.

SLUCM was configured using four surface layers of roof (each $5 \mathrm{~cm}$ thick), wall (each $5 \mathrm{~cm}$ thick) and road $(5,25$, 50 and $75 \mathrm{~cm}$ ). The inner building temperature was set to a constant value of $298 \mathrm{~K}$.

Land use information was compiled using Corine2006 (EEA, 2012) data set and where it does not provide informa- tion (e.g. western Ukraine, Belarus), the Global Land Cover 2000 (GLC, 2000) database is used.

In particular, urban category is a compilation of continuous urban fabric land use type (cat. 1.1.1 from Corine2006) and artificial surface and associated areas (cat. 22 from GLC2000). Sub-urban category is identical to discontinuous urban fabric land use type (cat. 1.1.2 from Corine2006). Figure 2 presents the model domain with orography and urban land coverage.

Both land use types (urban and sub-urban) are characterized by specific urban geometry parameters (Table 1). The urban canopy parameters used in the SLUCM are the ones used in the WRF implementation of SLUCM (see Chen et al., 2011) modified to better describe the urban environment in cities in central Europe. Building heights were increased and are similar to those used for Polish cities by Struzewska and Kaminski (2012). Similar values were used by Martilli (2002) who focused on European cities as well. The road/street widths are also more suited to the targeted region and follow the values of Martilli (2002) or Ratti et al. (2001). The values for the AHR represent the annual average while the model internally calculates the monthly variation (the yearly amplitude is about 70 to $130 \%$ of the annual average value for July to January, respectively). They follow the case of a Polish city (Kłysik, 1995) but are also in line with the measurements from the city of Toulouse, France (Pigeon et al., 2007), with the consideration that the central European climate during winter is colder, bringing higher heating and larger heat release. Other parameters of the urban canopy in SLUCM are unchanged from the WRF implementation. It has to be noted that these values are rough estimates and describe all urban (and suburban) surfaces within the domain. However, there are large differences between cities, and even within our $2 \mathrm{~km} \times 2 \mathrm{~km}$ subgrid box, these values can vary substantially. Because of this, a possible uncertainty is brought into the results. To assess its magnitude, a sensitivity test to the key urban parameters was included in this study (Sect. 3.3).

Table 2 summarizes the experiments performed using the RegCM4.2 extended with the SLUCM. The NOURBAN experiment corresponds to the case with no urban coverage, i.e. the urban land use types were changed to the dominating adjacent land use categories, usually "crop" and "forest", similarly as in Trusilova et al. (2008). The SLUCM experiments considers urban surfaces, treating them with the SLUCM urban canopy parameterization. The mentioned experiments were run for a 5-year period between 2005-2009. The impact of urban surfaces on climate was then evaluated as the difference between SLUCM and NOURBAN for the selected meteorological fields.

To analyse the sensitivity of the results to the key urban parameters, four additional simulations were performed with modifications of the building height, street width, roof albedo and AHR (Table 2). These simulations were performed for a 1-year period (2005) and are titled as SEN1-4. 

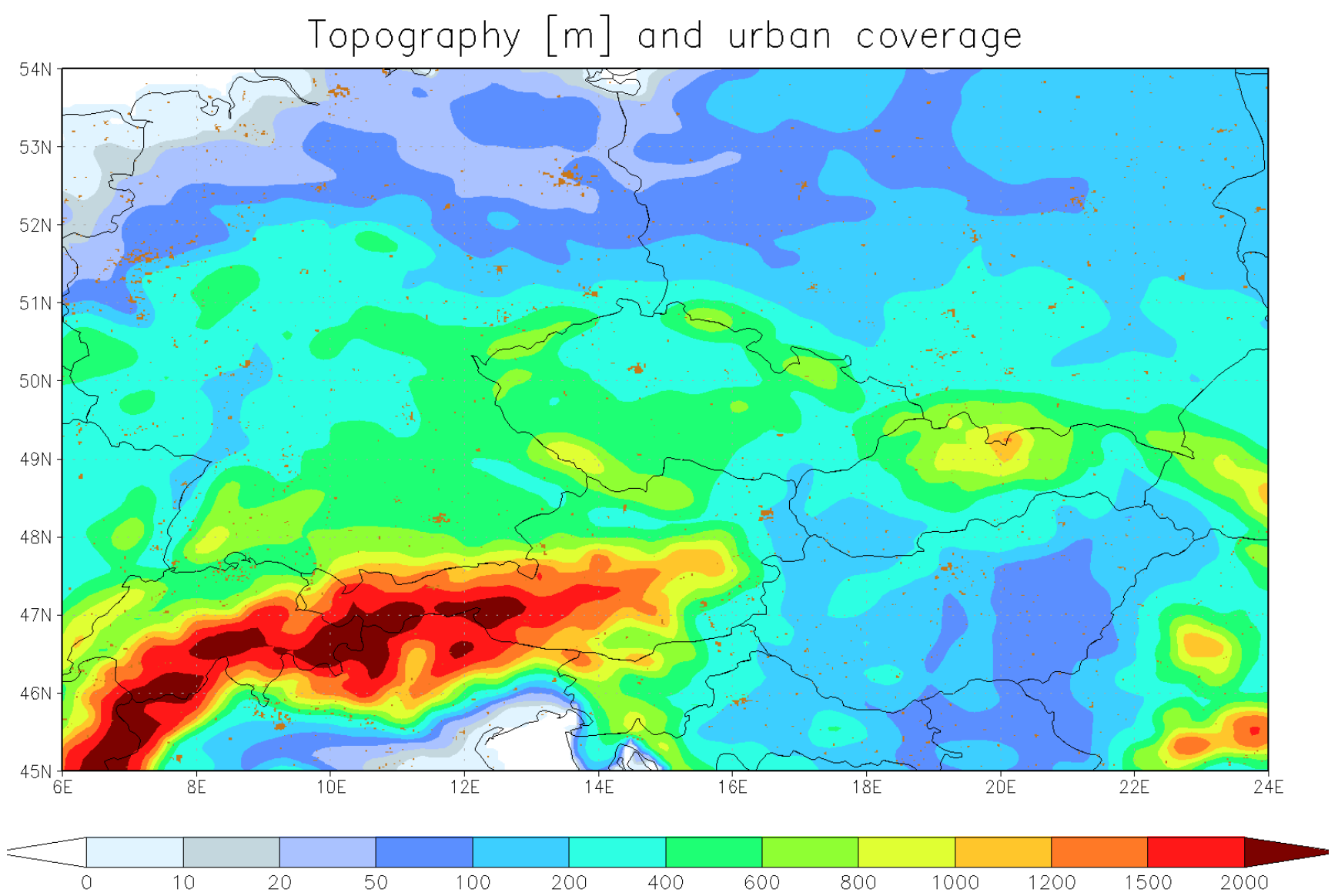

Figure 2. The model domain with orography in $\mathrm{m}$ at $10 \mathrm{~km} \times 10 \mathrm{~km}$ resolution and urban coverage at $2 \mathrm{~km} \times 2 \mathrm{~km}$ resolution (fine-scale brown elements).

In the noSUBBATS experiment, it is examined how the results change if the surface model resolution equals to the dynamical resolution (i.e. $10 \mathrm{~km}$ ). As a reference simulation, a similar experiment is performed without SUBBATS and without any urban treatment (denoted noSUBBATS/NOURBAN). Finally, to see the extent of the urban surfaces' influence on remote areas, an experiment titled PRAGUE was performed, where only the city of Prague was treated as urban surface. Here, Prague is defined as a squared region of $50 \mathrm{~km} \times 50 \mathrm{~km}$ area centred on the city's midpoint.

RegCM4.2 was run for the year 2004 without SLUCM as a spin-up time, and all the experiments were restarted from this run.

\section{Results}

\subsection{Spatial distribution of the impact of urban surfaces}

This section presents the spatial (horizontal and vertical) distribution of the meteorological impacts of urbanized surfaces. To evaluate their seasonal dependence, the winter (DJF; December-February) and summer (JJA; June-August) impact are presented separately. Furthermore, as the meteorological regime in the urban environment differs between day and night-time, we will discuss separately the day and night impacts as well. Shaded areas in all "spatial" figures represent statistically significant differences at the $95 \%$ level according to the one sample $t$ test of the difference of two fields (for variables with approximately Gaussian distribution of the differences), except for wind speed and precipitation, where the non-parametrical sign-test was applied.

Figure 3 presents the day (upper panels) and night-time (bottom panels) impacts of urban surfaces on the $2 \mathrm{~m}$ air temperature averaged over winter (left) and summer (right). In general, the impact is highest over highly urbanized areas indicating a well pronounced UHI effect. The location of cities such as Berlin, Prague, Vienna, Budapest, Munich or Warsaw is well recognized through the UHI effect. In winter, the impact is generally lower, reaching values up to $0.4 \mathrm{~K}$ over daytime for many cities. However, the impact is statistically significant even over rural regions far from larger cities, with up to $0.05 \mathrm{~K}$ temperature increase. During night, the impact is very small and rather noisy, though there is an indication 
Table 1. Urban canopy parameters of SLUCM as implemented in RegCM4.2 for the central European region.

\begin{tabular}{lccc}
\hline Parameter & Unit & Urban & Sub-urban \\
\hline$h$ (building height) & $\mathrm{m}$ & 20 & 15 \\
$l_{\text {roof }}$ (roof width) & $\mathrm{m}$ & 20 & 15 \\
$l_{\text {road (street width) }}$ & $\mathrm{m}$ & 15 & 20 \\
$\mathrm{AH}$ (anthropogenic heat) & $\mathrm{W} \mathrm{m}^{-2}$ & 70 & 30 \\
$F_{\mathrm{urb}}$ (urban fraction) & - & 0.9 & 0.7 \\
$C_{\mathrm{R}}$ (heat capacity of the roof) & $\mathrm{J} \mathrm{m}^{-3} \mathrm{~K}^{-1}$ & $1.0 \times 10^{6}$ & $1.0 \times 10^{6}$ \\
$C_{\mathrm{W}}$ (heat capacity of the wall) & $\mathrm{J} \mathrm{m}^{-3} \mathrm{~K}^{-1}$ & $1.0 \times 10^{6}$ & $1.0 \times 10^{6}$ \\
$C_{\mathrm{G}}$ (heat capacity of the road) & $\mathrm{J} \mathrm{m}^{-3} \mathrm{~K}^{-1}$ & $1.4 \times 10^{6}$ & $1.4 \times 10^{6}$ \\
$\lambda_{\mathrm{R}}$ (thermal conductivity of the roof) & $\mathrm{J} \mathrm{m}^{-1} \mathrm{~s}^{-1} \mathrm{~K}^{-1}$ & 0.67 & 0.67 \\
$\lambda_{\mathrm{W}}$ (thermal conductivity of the wall) & $\mathrm{J} \mathrm{m}^{-1} \mathrm{~s}^{-1} \mathrm{~K}^{-1}$ & 0.67 & 0.67 \\
$\lambda_{\mathrm{G}}$ (thermal conductivity of the road) & $\mathrm{J} \mathrm{m}^{-1} \mathrm{~s}^{-1} \mathrm{~K}^{-1}$ & 0.40 & 0.40 \\
$\alpha_{\mathrm{R}}$ (albedo of the roof) & - & 0.20 & 0.20 \\
$\alpha_{\mathrm{W}}$ (albedo of the wall) & - & 0.20 & 0.20 \\
$\alpha_{\mathrm{G}}$ (albedo of the road) & - & 0.20 & 0.20 \\
$\varepsilon_{\mathrm{R}}$ (emissivity of the roof) & - & 0.90 & 0.90 \\
$\varepsilon_{\mathrm{W}}$ (emissivity of the wall) & - & 0.90 & 0.90 \\
$\varepsilon_{\mathrm{G}}$ (emissivity of the road) & - & 0.95 & 0.95 \\
$Z_{0 \mathrm{R}}$ (roughness length for momentum over roof) & $\mathrm{m}$ & 0.01 & 0.01 \\
\hline
\end{tabular}

Table 2. Different experiments performed with the RegCM4.2/SLUCM couple. The sensitivity runs are described in terms of the percentage change of the selected urban parameter with respect to the value listed in Table 1.

\begin{tabular}{lccccc}
\hline Experiment & Urban treatment & Period & SLUCM parameters & SUBBATS & Urban surfaces \\
\hline NOURBAN & No & $2005-2009$ & - & Yes & - \\
SLUCM & Yes & $2005-2009$ & Default - see Table 1 & Yes & All \\
SEN1 & Yes & 2005 & $50 \%$ building height & Yes & All \\
SEN2 & Yes & 2005 & $50 \%$ road width & Yes & All \\
SEN3 & Yes & 2005 & $200 \%$ roof albedo & Yes & All \\
SEN4 & Yes & 2005 & $50 \%$ AHR & Yes & All \\
noSUBBATS & Yes & $2005-2009$ & Default - see Table 1 & No & All \\
noSUBBATS/NOURBAN & No & $2005-2009$ & - & No & - \\
PRAGUE & Yes & $2005-2009$ & Default - see Table 1 & Yes & Prague only \\
\hline
\end{tabular}

for a slight temperature decrease over cities up to $-0.1 \mathrm{~K}$ (over Berlin, Prague, Vienna, Budapest and others).

A much stronger impact is modelled during summer. During the day, temperature increased almost everywhere over the domain, with a peak over the cities less pronounced than during night-time. The impact exceeds $0.4 \mathrm{~K}$ over a large part of the domain far from urbanized centres and is highest over Budapest $(0.7 \mathrm{~K})$ and Milan $(1.0 \mathrm{~K})$. As expected, the most pronounced impact is modelled during the summer night-time when the UHI phenomenon is considered to be the strongest. Over many cities, the temperature increase exceeds 1.5 K (Berlin, Prague, Vienna, Budapest, Munich, Milan, etc.), and is also substantial over rural areas, reaching $0.2 \mathrm{~K}$.

The changes in the height of the planetary boundary layer (ZPBL) are presented in Fig. 4. The daytime impacts are usually more prominent, indicating an increase up to $50 \mathrm{~m}$ in winter and up to $200 \mathrm{~m}$ in the summer months. In winter, the statistically significant changes are usually limited to larger cities, while in summer, large rural areas are also marked with significant ZPBL increase (up to $50 \mathrm{~m}$ over most of the domain). During winter night-time, just a limited number of locations exhibit a significant change, with up to $-20 \mathrm{~m}$ decrease. In summer, extensive areas encounter ZPBL increase due to urbanized surfaces (up to $100 \mathrm{~m}$ ), not limited to large cities only. During night-time, the impact of cities is much smaller and is characterized by an increase of ZPBL (up to $50 \mathrm{~m}$ ). However, over rural areas, a statistically significant decrease is modelled (up to $-20 \mathrm{~m}$ ).

The impact on $10 \mathrm{~m}$ wind velocity (Fig. 5) depends largely on whether winter or summer conditions and day or night are considered. In winter daytime, urban effects can result in both small increase (usually in the vicinity of the cities) and small decrease of wind speed (located over cities). A more uniform picture is visible for the night-time changes in winter: there is an evident wind speed reduction especially over the cities up to $-0.6 \mathrm{~ms}^{-1}$. The decrease over rural areas is small $\left(-0.1 \mathrm{~ms}^{-1}\right)$ and usually statistically insignificant. The impact of cities on wind velocity in summer is characterized, during daytime, by a decrease just over the cities (up 

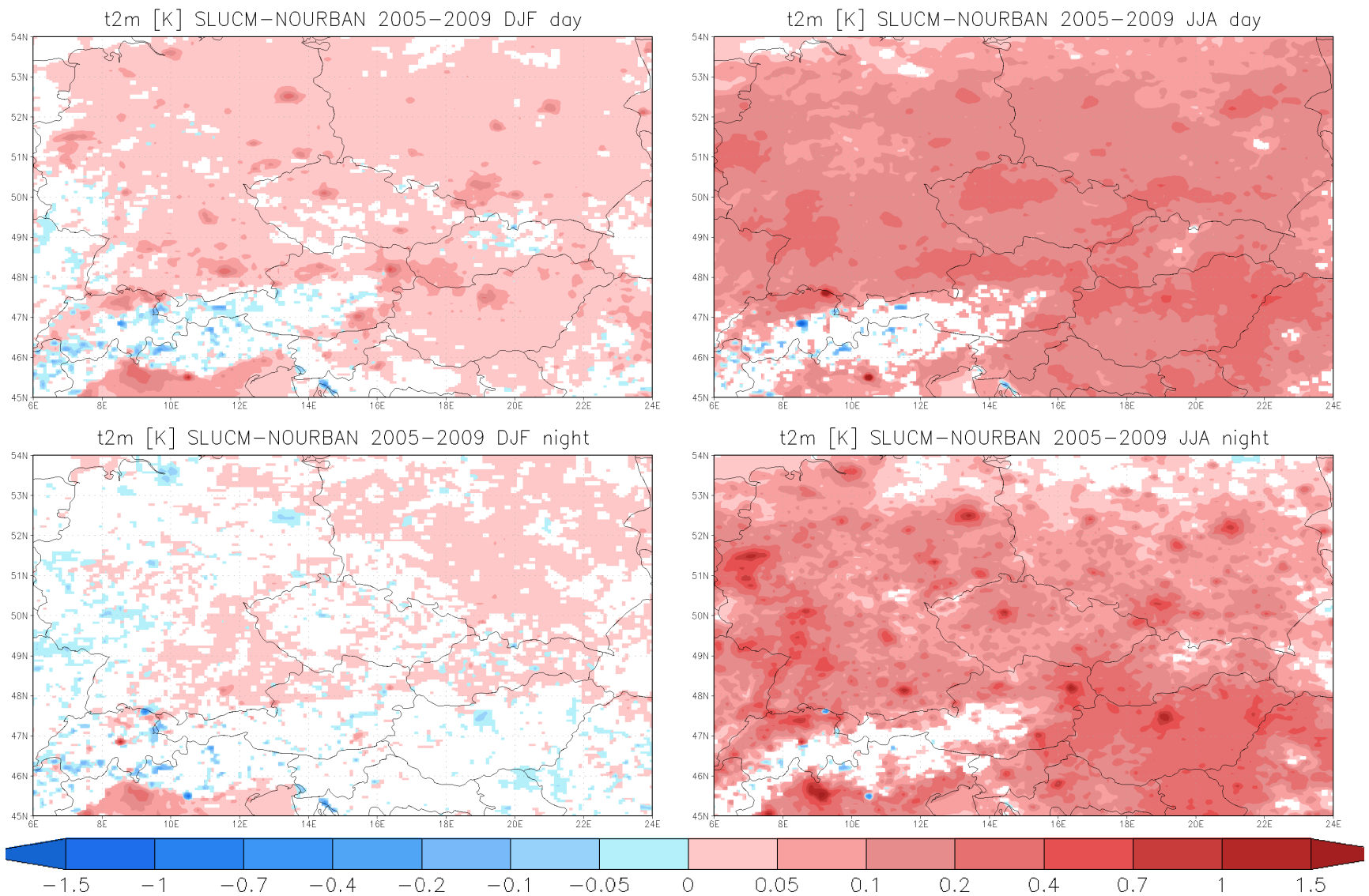

Figure 3. The impact of urbanized surfaces on the winter (left) and summer (right) near surface temperature for day (above) and night-time (bottom) conditions in K averaged over the years 2005-2009. Shaded areas represent statistically significant differences on the 95\% level.

to $-0.2 \mathrm{~m} \mathrm{~s}^{-1}$ ), with a small but statistically significant increase just around the cities (up to $0.2 \mathrm{~m} \mathrm{~s}^{-1}$ ). During nighttime, urban surfaces seem to increase the wind speed up to $0.3 \mathrm{~m} \mathrm{~s}^{-1}$, although this is not evident for all major urban centres throughout central Europe, but rather limited to cities over the western part of the domain.

As the variables related to water budget (evaporation, humidity, precipitation) were influenced significantly only during summer, we present results only for this season. Decrease of evaporation commonly associated with urban surfaces comes along with reduced specific humidity that can be well seen in Fig. 6 (left). During summer, especially for daytime, the decrease of specific humidity can exceed $-1 \mathrm{~g} \mathrm{~kg}^{-1}$ over cities (peaking at $-1.3 \mathrm{~g} \mathrm{~kg}^{-1}$ ). During night, the decrease is of smaller magnitude, up to $-0.6 \mathrm{~g} \mathrm{~kg}^{-1}$. The decrease is not limited to larger central European cities only, but it affects almost the entire domain for both day and night.

The introduction of urban surfaces has an impact on the precipitation rates in our simulations as well (Fig. 6, left). The effect is statistically significant during summer daytime in connection with the decreased evaporation, when it is characterized with a large decrease over cities exceeding
-2 mm day $^{-1}$, mostly over Budapest, Katowice, Warsaw, Vienna, Prague, Munich and the Ruhr region in Germany. The precipitation changes over areas without dominant urban surfaces are usually statistically insignificant. Near a few cities, a slight but statistically significant increase of precipitation is modelled as well, mainly in central Germany and Poland, up to $0.5 \mathrm{~mm} \mathrm{day}^{-1}$.

Apart from the urban induced changes to the horizontal distribution of meteorological fields, perturbations to the vertical structure of temperature are presented here. Figure 7 illustrates the temperature vertical cross-section along the $50^{\circ} \mathrm{N}$ latitude, which crosses several urbanized areas. A statistically significant warming is indicated up to about $1.7 \mathrm{~km}$ in summer, i.e. approximately in the planetary boundary layer (PBL). The warming is most intense just above the surface, but remains above $0.2 \mathrm{~K}$ almost across the entire PBL depth during both day and night. The warming due to urban surfaces spreads to lower elevations $(300 \mathrm{~m})$ in winter, due to reduced vertical mixing, and is less significant during the night. Above the boundary layer in summer (between altitudes 1.7 and $10 \mathrm{~km}$ ), statistically significant cooling is modelled, especially during daytime (up to $-0.1 \mathrm{~K}$ ). Finally there 


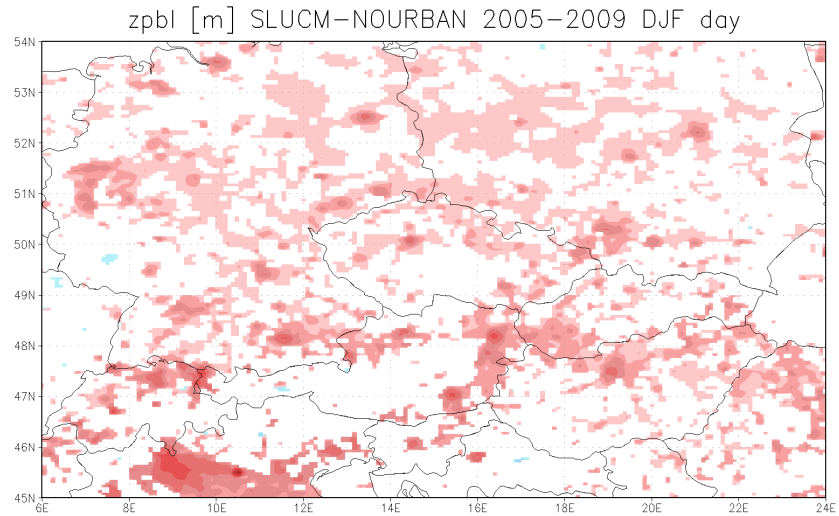

zpbl [m] SLUCM-NOURBAN 2005-2009 DJF night
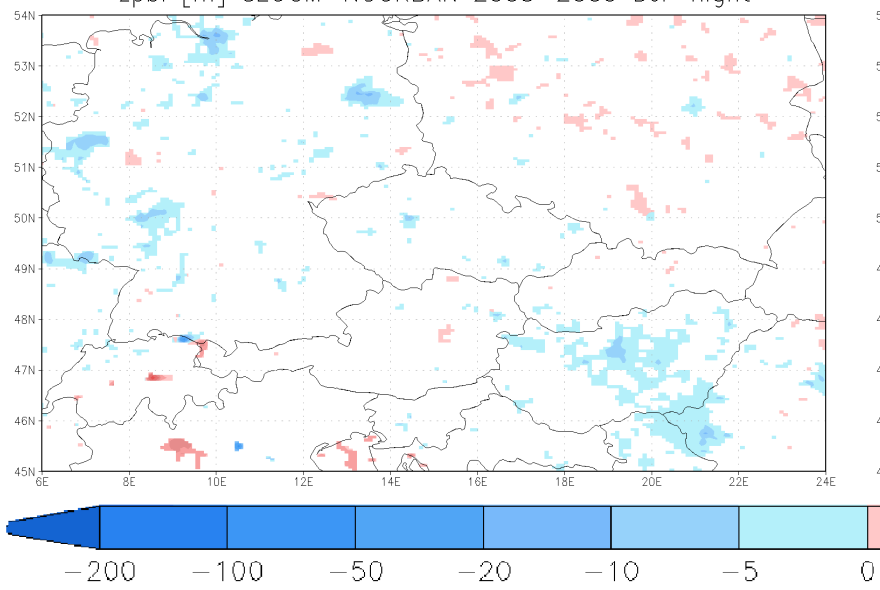

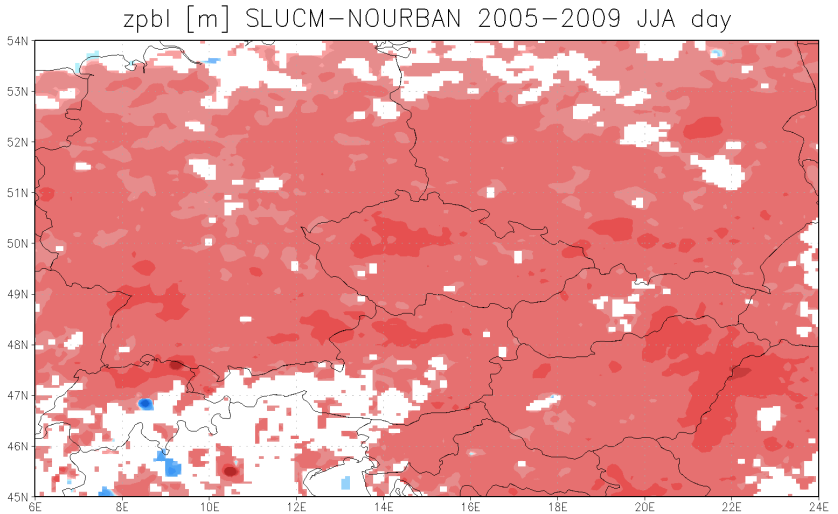

zpbl [m] SLUCM-NOURBAN 2005-2009 JJA night
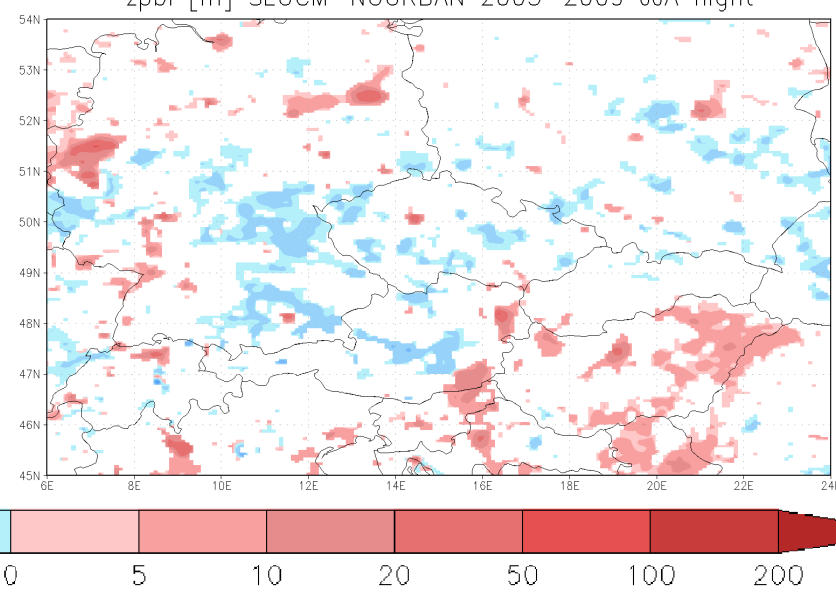

Figure 4. Same as Fig. 3 but for the PBL height in metres.

is an indication of warming above approximately $10 \mathrm{~km}$ (up to $0.05 \mathrm{~K}$ ), but mostly statistically insignificant. In winter, no statistically significant impact is modelled above the PBL.

\subsection{Monthly and daily temperature profiles and comparison with observations}

This section presents the impact of urbanized surfaces on the monthly and hourly temperature variations over selected cities in central Europe. Table 3 shows the monthly $2 \mathrm{~m}$ temperatures averaged over the years 2005-2009 from both NOURBAN and SLUCM simulations for the summer months (June, July and August). The corresponding values from the E-OBS gridded observational data set (Haylock et al., 2008) are included for comparison as well. A systematic underestimation of temperatures is revealed throughout the whole year (up to $-4 \mathrm{~K}$ over Berlin in spring - not presented here). The table clearly shows, that, during summer months, the negative model bias is eliminated (or at least reduced) by introducing the SLUCM parameterization for the urban surfaces. This holds especially for Munich and $\mathrm{Bu}-$ dapest.

The 2005-2009 average hourly variation of $2 \mathrm{~m}$ temperatures for selected cities is presented in Fig. 8. To obtain infor- mation about the magnitude of the UHI effect, the figure includes the average temperature from the vicinity of the cities (defined as approximately a $10 \mathrm{~km}$ wide belt $20 \mathrm{~km}$ from the city centres) taken from the SLUCM experiment. In our simulations, the UHI develops during noon hours and reaches its maximum around $10 \mathrm{p} . \mathrm{m}$. to midnight local time at about $0.5 \mathrm{~K}$ on annual average. The UHI diminishes around 6 a.m.

During the morning hours until noon, a weak UCI (urban cool island) develops over Berlin, Budapest and $\mathrm{Mu}-$ nich, with maximum temperature decrease of -0.5 to $-0.1 \mathrm{~K}$ reaching at around 9-11 a.m.

It is interesting to see that the city temperatures for configuration disregarding the urban surfaces (NOURBAN, blue line) are lower than the temperatures accounting for urban effect in the vicinity of cities during the maximum UHI development (SLUCM, orange line), by up to $0.1 \mathrm{~K}$ on annual average. This is consistent with our spatial results, which showed that the impact of urban surfaces is not limited to the air column over large cities, but is spread over remote areas as well, as seen in Fig. 3.

For more detailed analysis, hourly station data from three locations in Prague are used to compare the observed hourly temperature variations and the modelled summer UHI. One 

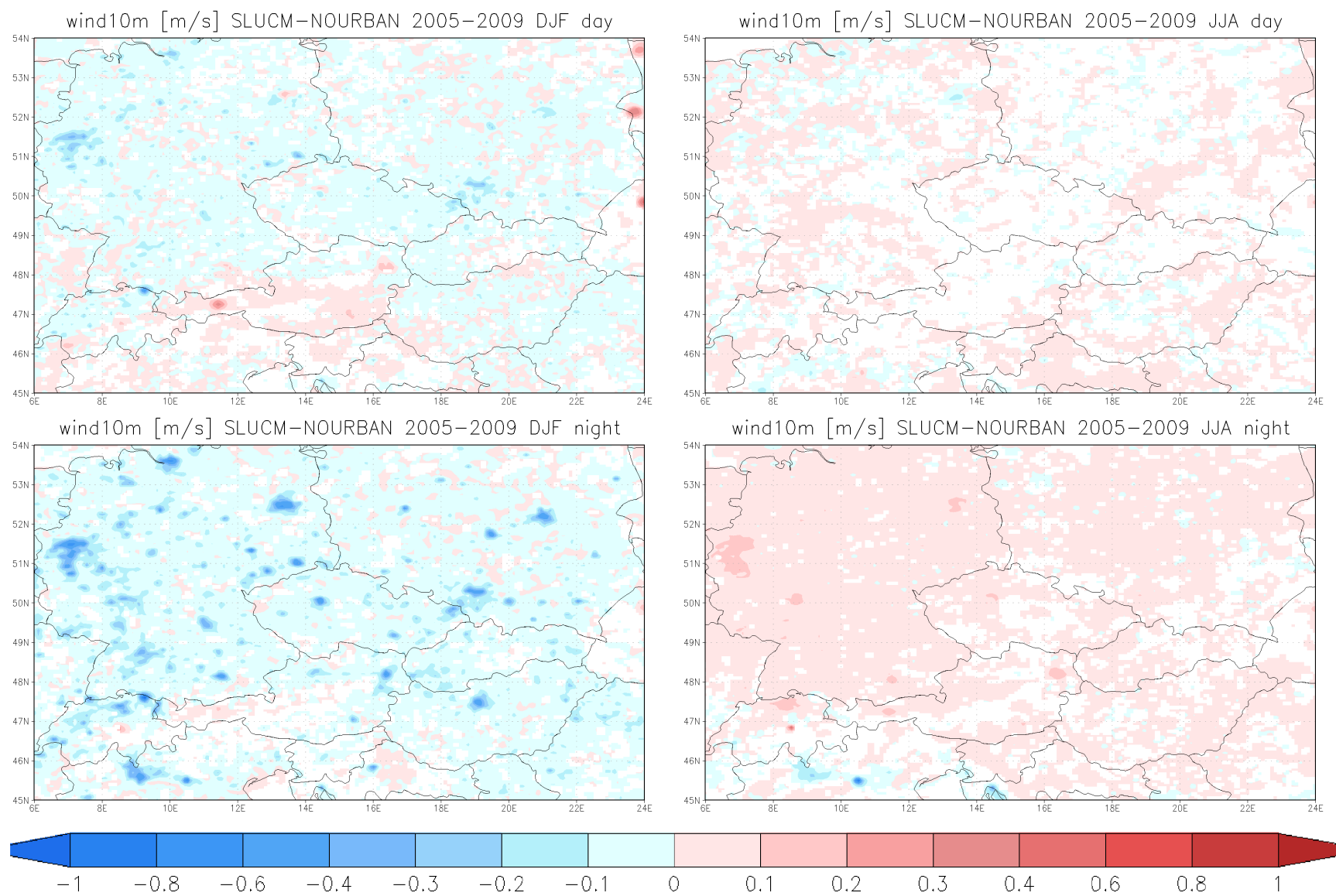

Figure 5. Same as Fig. 3 but for the wind velocity at $10 \mathrm{~m}^{\text {in }} \mathrm{ms}^{-1}$.

Table 3. The mean 2005-2009 monthly summer $2 \mathrm{~m}$ temperatures averaged over selected cities in central Europe for the NOURBAN, SLUCM runs and extracted from E-OBS observational data.

\begin{tabular}{|c|c|c|c|c|c|c|c|c|c|c|c|c|c|c|c|}
\hline & \multicolumn{3}{|c|}{ Prague } & \multicolumn{3}{|c|}{ Vienna } & \multicolumn{3}{|c|}{ Budapest } & \multicolumn{3}{|c|}{ Munich } & \multicolumn{3}{|c|}{ Berlin } \\
\hline & NOURBAN & SLUCM & E-OBS & NOURBAN & SLUCM & E-OBS & NOURBAN & SLUCM & E-OBS & NOURBAN & SLUCM & E-OBS & NOURBAN & SLUCM & E-OBS \\
\hline June & 15.8 & 16.4 & 18.0 & 18.6 & 19.6 & 21.0 & 19.6 & 20.3 & 21.0 & 15.7 & 16.5 & 19.0 & 15.9 & 16.4 & 18.0 \\
\hline July & 18.4 & 18.9 & 20.0 & 21.2 & 22.1 & 22.0 & 22.4 & 22.9 & 23.0 & 18.4 & 19.1 & 21.0 & 18.4 & 19.0 & 19.0 \\
\hline August & 16.9 & 17.4 & 18.0 & 19.7 & 20.6 & 20.0 & 20.4 & 21.0 & 21.0 & 16.7 & 17.4 & 18.0 & 16.6 & 17.1 & 17.0 \\
\hline
\end{tabular}

station lies in the inner centre of Prague, where the maximum UHI is expected, while two are located in the vicinity of the city centre (about $10-15 \mathrm{~km}$ far). The results are plotted in Fig. 9. Solid lines stand for the city centre model (NOURBAN-blue, SLUCM-pink) and station (orange) data. The dashed and dash-dotted lines correspond to the two stations in Prague's vicinity. As seen already for the monthly data (Table 3 ), there is a negative model bias present throughout the day. When not considering urban surfaces (i.e. the NOURBAN experiment), this bias reaches, during late evening hours $-3 \mathrm{~K}$ in city centre and around $-2 \mathrm{~K}$ for the stations in the city's vicinity. When the SLUCM surface model is turned on, an evident model bias reduction is seen during afternoon and evening hours in the city centre, i.e. when the UHI achieves its peak. The UHI presence is fur- thermore indicated by lower temperatures in the city vicinity in both the SLUCM experiment (by almost $0.5 \mathrm{~K}$ ) and in the measurements (up to $1 \mathrm{~K}$ ). When urban surfaces are not considered (NOURBAN experiment, blue line), the hourly temperature profile is almost the same for the city centre and for the two stations in the city vicinity as no urban heat island effect is modelled. In the measured data, a clear indication for the urban cool island effect is identifiable (with the vicinity of Prague being warmer than the centre by around $0.3 \mathrm{~K}$ ), while very weak UCI is present in the model data (up to $-0.05 \mathrm{~K}$ ).

\subsection{Sensitivity tests}

The urban canopy model can be configured with a whole range of parameters describing the geometry and the thermomechanical properties of the surfaces typical for the ur- 
q2m [g/kg] SLUCM-NOURBAN 2005-2009 JJA day

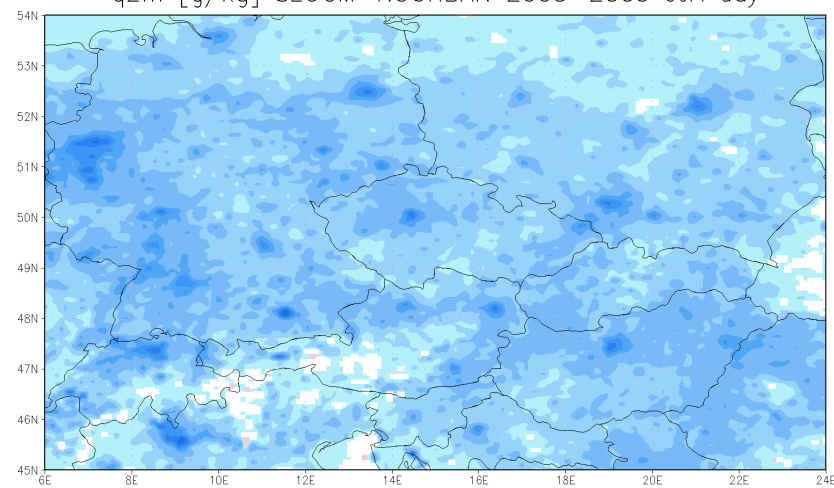

q2m [g/kg] SLUCM-NOURBAN 2005-2009 JJA night

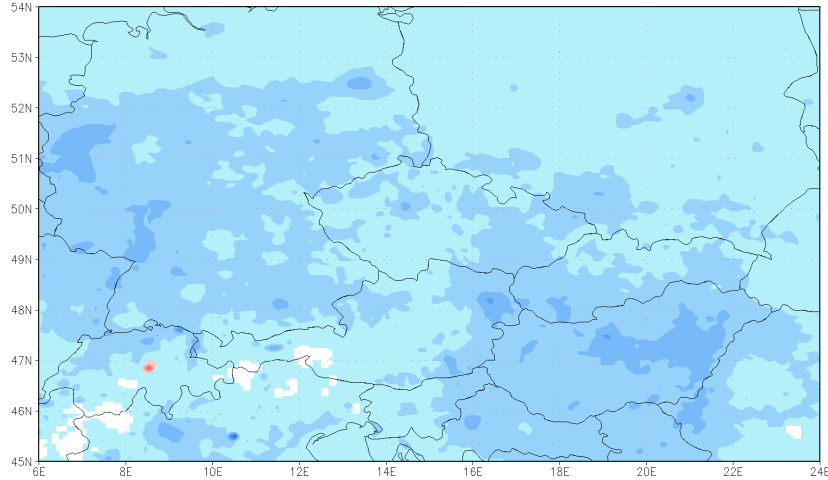

$\operatorname{tpr}[\mathrm{mm} /$ day] SLUCM-NOURBAN 2005-2009 JJA day

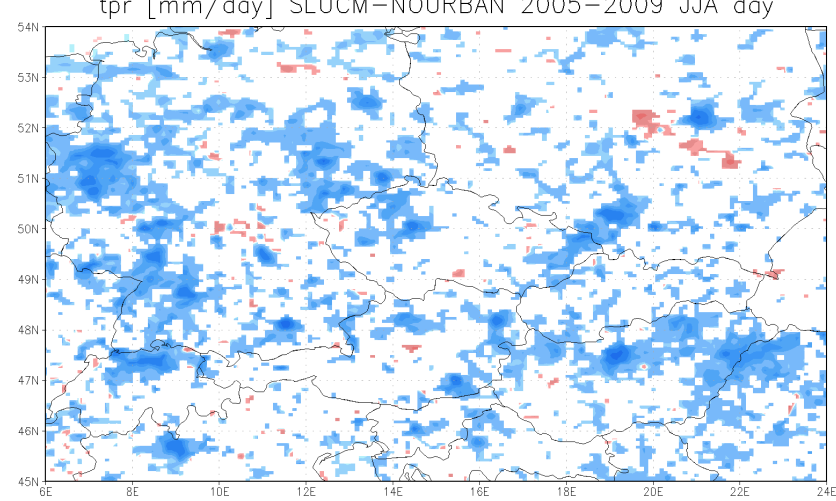

tpr [mm/day] SLUCM-NOURBAN 2005-2009 JJA night

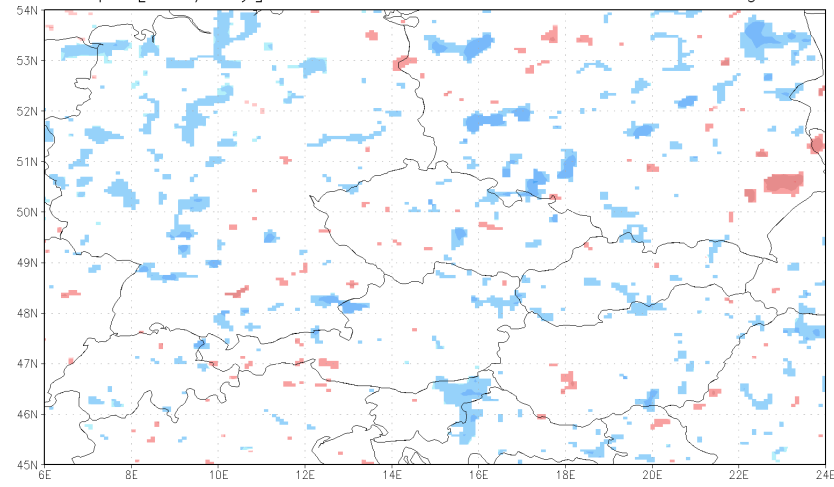

$\begin{array}{lllllllllllllll}-1.3 & -1 & -0.8 & -0.6 & -0.4 & -0.2 & -0.1 & 0 & 0.1 & 0.2 & 0.4 & 0.6 & 0.8 & 1 & 1.3\end{array}$

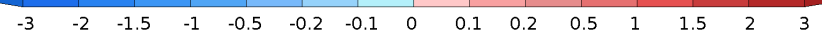

Figure 6. The impact of urbanized surfaces on summer surface specific humidity in $\mathrm{g} \mathrm{kg}^{-1}$ (left) and total precipitation rate in mm day ${ }^{-1}$ (right) for day (above) and night-time (bottom) conditions. Shaded areas represent statistically significant differences on the $95 \%$ level.

ban environment (Table 1). These parameters are set globally without any spatial variation within the domain. Furthermore, for a given grid box $(2 \mathrm{~km} \times 2 \mathrm{~km}$ for our subgrid treatment of surface processes), these parameters may, in general, vary from street to street, from building to building. Finally, even choosing these parameters to match the average conditions in urban canopy for a given domain (region) is a challenging task.

Considering the above mentioned, there is a certain degree of uncertainty with the results originating in the estimation of the SLUCM parameters. To evaluate this uncertainty, an additional set of simulations is performed for the year 2005 with modified urban canopy parameters: street width $(50 \%$ reduction); building height (50\% reduction); roof albedo (doubled value); and anthropogenic heat release (50\% reduction) corresponding to sensitivity experiments SEN1, SEN2, SEN3 and SEN4, respectively. The first two parameters are of key importance in describing the city's geometry; the third parameter is important in urban mitigation strategies for reducing the UHI. The fourth one is marked with high uncertainty as well, as very few estimations or measurements exist on AHR.
The change of spatial distribution of selected meteorological parameters after introducing the modifications of the urban parameters is evaluated as the difference between the corresponding SENx experiment and SLUCM experiment. We focused on the summer night-time average change when the impacts are large, and in case of the SEN3 sensitivity experiment (reduced albedo) the average summer daytime change is shown, as albedo is relevant for the reflected solar radiation.

Figure 10 presents impact on near surface temperature. When reducing building height by $50 \%$, significant temperature reduction occurs up to $-0.4 \mathrm{~K}$ over most of the large urbanized areas (cities such Budapest, Vienna, Prague, Berlin, Munich or Warsaw), which corresponds to a $30 \%$ reduction of the absolute impact on temperature (Fig. 3). The reduction of street width by $50 \%$ usually increases summer night-time temperatures up to $0.1-0.2 \mathrm{~K}$, as seen especially over Berlin, Prague, Munich, Vienna. This means an intensification of the UHI phenomenon by about $20 \%$. Lower roof albedo reflects more solar radiation and this also affects the near surface temperatures during day. Over many cities and even over larger areas around cities, the temperature reduction reaches -0.1 to $-0.2 \mathrm{~K}$, which significantly reduces the absolute im- 


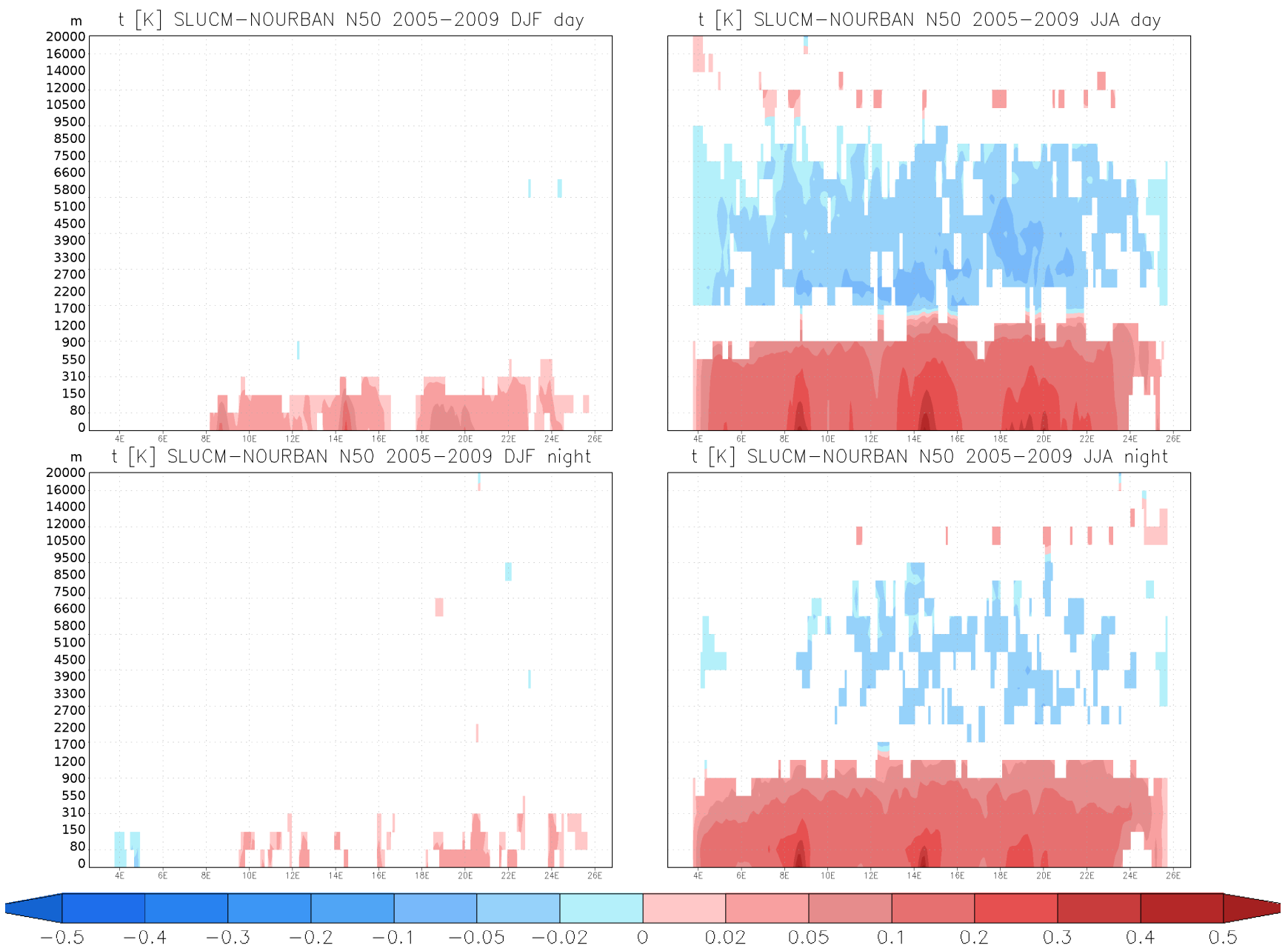

Figure 7. The impact of urbanized surfaces on the winter (left) and summer (right) vertical cross-section of temperature along the $50^{\circ} \mathrm{N}$ latitude for day (above) and night-time (bottom) conditions in K averaged over the years 2005-2009. The vertical axis denotes the average model levels heights in metres. Shaded areas represent statistically significant differences on the $95 \%$ level.

pact of urban surfaces on temperature seen in Fig. 3. Finally, the AHR reduction reduces also the night-time temperatures by up to $-0.2 \mathrm{~K}$, not only over cities but over areas far from large urbanized centres.

The effects on the PBL height (ZPBL) change within the sensitivity tests are plotted in Fig. 11. The impact on ZPBL is spatially noisier than for the temperature. For the $50 \%$ building height reduction, there is an indication of statistically significant ZPBL decrease of up to $-20 \mathrm{~m}$ over cities (especially Berlin, Vienna and Warsaw). For the $50 \%$ street width reduction, the ZPBL change pattern is even noisier, without clear impact (slight increase for a few cities, but decrease for others). A more pronounced impact is modelled for the increased roof albedo, when due to enhanced reflection and to lower surface temperatures the PBL stabilizes, decreasing its height. This reduction reaches $-30 \mathrm{~m}$ over large areas, especially around cities. Finally, when decreasing the AHR, the
ZPBL is affected only slightly, with a decrease typically up to $-20 \mathrm{~m}$.

For other meteorological parameters, the spatial results of the sensitivity tests are not shown, only the changes for five selected cities. For completeness, we include the near surface temperature and ZPBL as well. The results are presented for both day and night in Table 4, where bold numbers mark statistically significant differences. The table indicates that, as already seen in Fig. 10, reducing building height causes temperature decrease, especially during the night (from -0.03 to $-0.1 \mathrm{~K}$ ), while reduced street width results in increased night-time temperatures $(0.01$ to $0.1 \mathrm{~K})$. The increased roof albedo reduces the daytime temperatures about $-0.1 \mathrm{~K}$ over cities in central Europe. Finally, reduced AHR causes temperature decrease during both day and night-time in cities up to $-0.1 \mathrm{~K}$. The ZPBL over cities decreases for reduced building height, increased albedo and reduced AHR, but a slight 


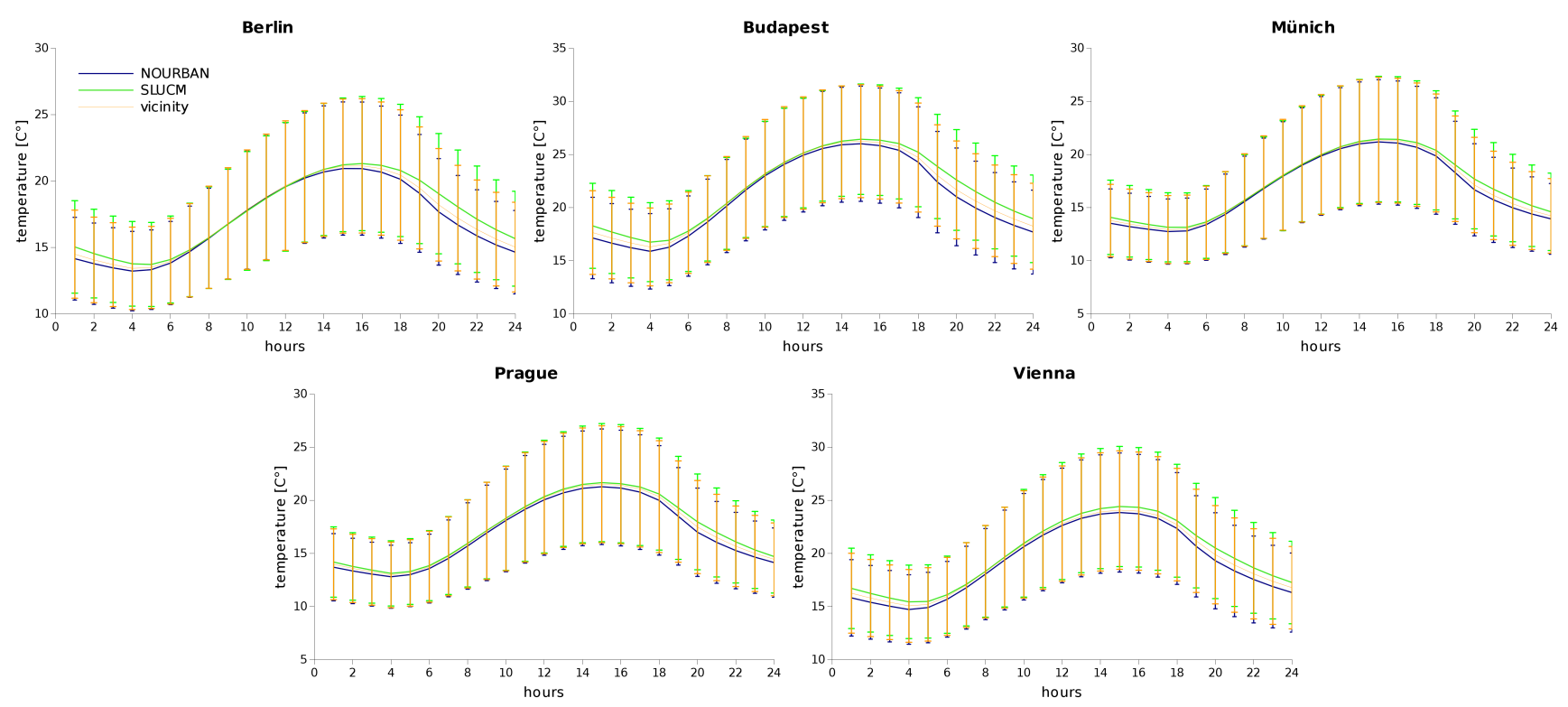

Figure 8. The mean 2005-2009 diurnal $2 \mathrm{~m}$ temperatures variation averaged over selected cities and over its vicinity in central Europe for the NOURBAN (blue), SLUCM (green - city, orange - vicinity) runs including vertical error bars.

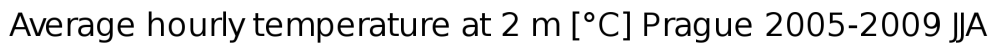

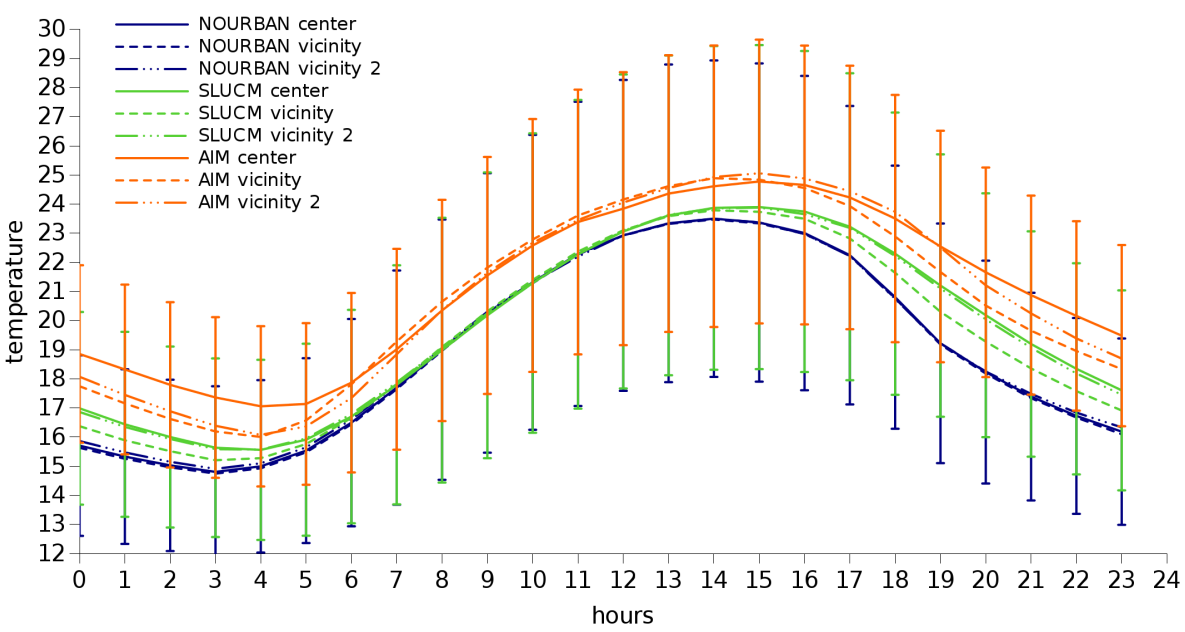

Figure 9. The mean summer diurnal $2 \mathrm{~m}$ temperatures variation in Prague for the NOURBAN experiment (blue), the SLUCM experiment (green) and for measurements (orange) from a station in the centre of Prague (solid line) and two stations from the vicinity of the city (dashed lines), including vertical error bars for the city centre series.

increase is modelled (especially during night-time) when decreasing street width.

The wind speed at $10 \mathrm{~m}$ usually increases (up to $0.3 \mathrm{~m} \mathrm{~s}^{-1}$ ) when reducing building height, especially during the daytime. It also further increases over each city during both night and daytime when reducing street width. The reduced roof albedo causes a slight decrease of wind speed which, however, is not statistically significant in most cases. The same is true for the impact of AHR reduction on the wind speed, although the numbers indicate slight decrease.
The $2 \mathrm{~m}$ specific humidity ( $\mathrm{q} 2 \mathrm{~m}$ ) tends to increase when lowering building heights and to decrease when reducing street width. Decrease occurs over cities as well when roof albedo is increased (especially over Budapest). Finally, with reduced AHR, q2m shows both increase and decrease, but usually of very small magnitude.

The sensitivity runs show a very small effect on total precipitation. When reducing building heights, the precipitation decreases significantly only over Budapest during daytime $\left(-0.4 \mathrm{~mm} \mathrm{day}^{-1}\right)$. Over the same city, the reduced street 

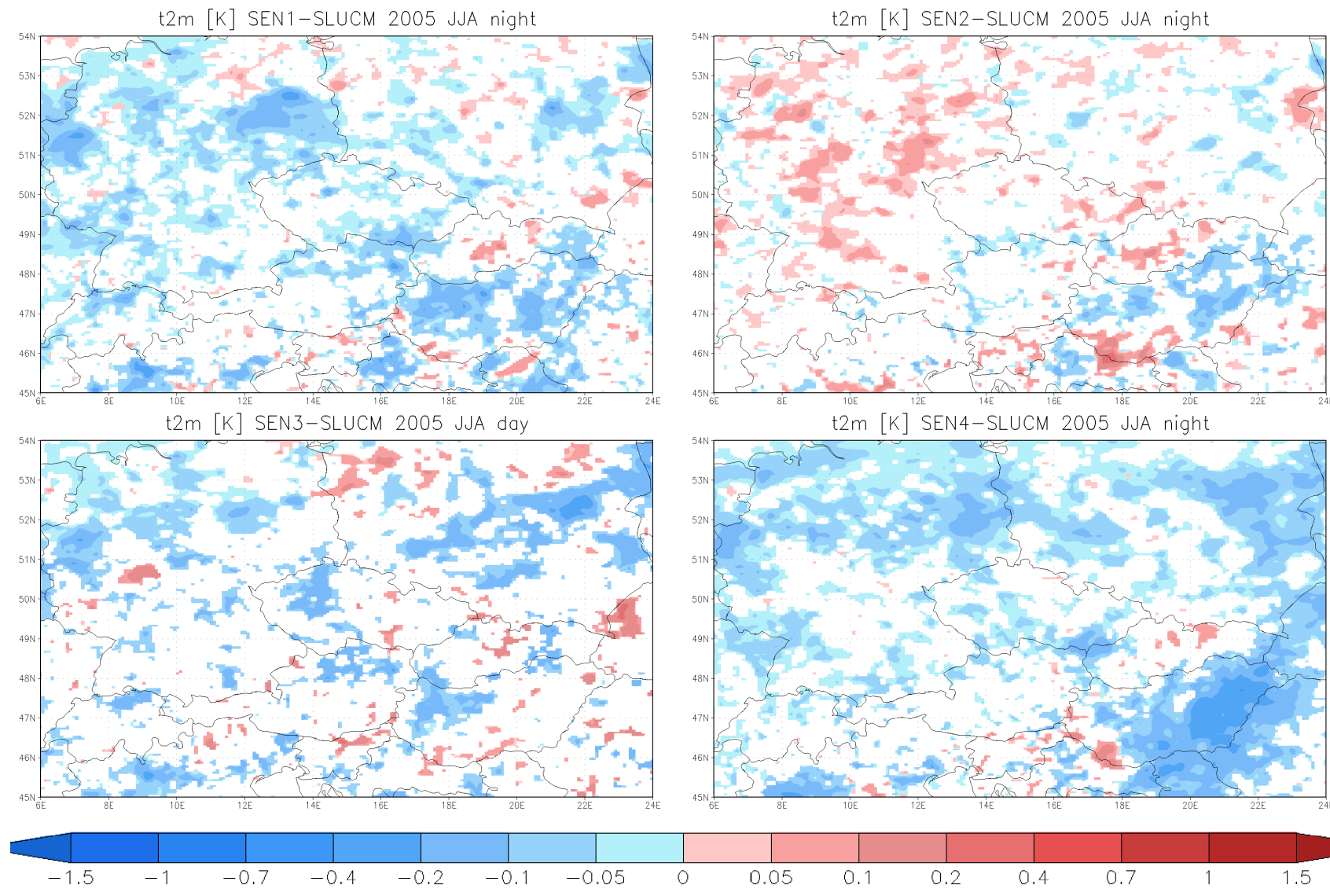

0.2

0.4

0.7

1.5

Figure 10. Sensitivity test: the impact of $50 \%$ reduction of building size (upper left), $50 \%$ reduction of street width (upper right), two times higher roof albedo (bottom left) and $50 \%$ reduction of AHR (bottom right) on the 2005 summer average near surface temperature for nighttime conditions (SEN1, SEN2 and SEN4) and daytime conditions (SEN3) in K. Shaded areas represent statistically significant differences on the $95 \%$ level.

width has significant impact on precipitation, with decrease during daytime but increase during the night. Reducing roof albedo leads to significant decrease of precipitation only over Prague and Budapest, over other cities the changes are ambiguous. Finally, reduced AHR leads to a statistically significant decrease of daytime precipitation only over Vienna and Berlin (up to $-1 \mathrm{mmday}^{-1}$ ).

It is also of interest how the results are influenced by the application of the subgrid surface treatment using the RegCM4.2 SUBBATS feature (at $2 \mathrm{~km} \times 2 \mathrm{~km}$ resolution in our case). Figure 12 shows the mean 2005-2009 summer temperature change for day and night evaluated without using SUBBATS. The daytime impact on near surface temperature is relatively smooth and large urban centres are difficult to identify. Maximum impact exceeds $0.2 \mathrm{~K}$, but can reach $1 \mathrm{~K}$ in Italy. During night, the urban centres become well visible with usually more than $1 \mathrm{~K}$ impact (often more than $1.5 \mathrm{~K}$, i.e. the impact is large over grid boxes with urban land use category (Fig. 2, left), but is significant even over grid boxes without urban land use category, often exceeding $0.1 \mathrm{~K})$.
Figure 13 presents the impact of urban surfaces corresponding only to Prague on the near surface temperature (including the SUBBATS treatment). The statistically significant temperature impact is limited to a small region (up to $150 \mathrm{~km}$ in diameter) around Prague for both day and night. The maximum impact corresponds to the Prague city centre and reaches 0.4 and $1.0 \mathrm{~K}$ for day and night, respectively, which is, for night-time, slightly less compared to the case when all the urban surfaces are considered (Fig. 3).

\section{Discussion and conclusions}

The regional impact of urban surfaces on the meteorological conditions over central Europe was evaluated, using the regional climate model RegCM4.2 extended with a singlelayer urban canopy model. We focused on the long-term effects performing 5 year simulations.

In terms of temperature, the largest impacts are modelled during summer night-time with up to $1.5 \mathrm{~K}$ higher temperatures than without considering urban surfaces. This is consistent with the maximum UHI development during evening 

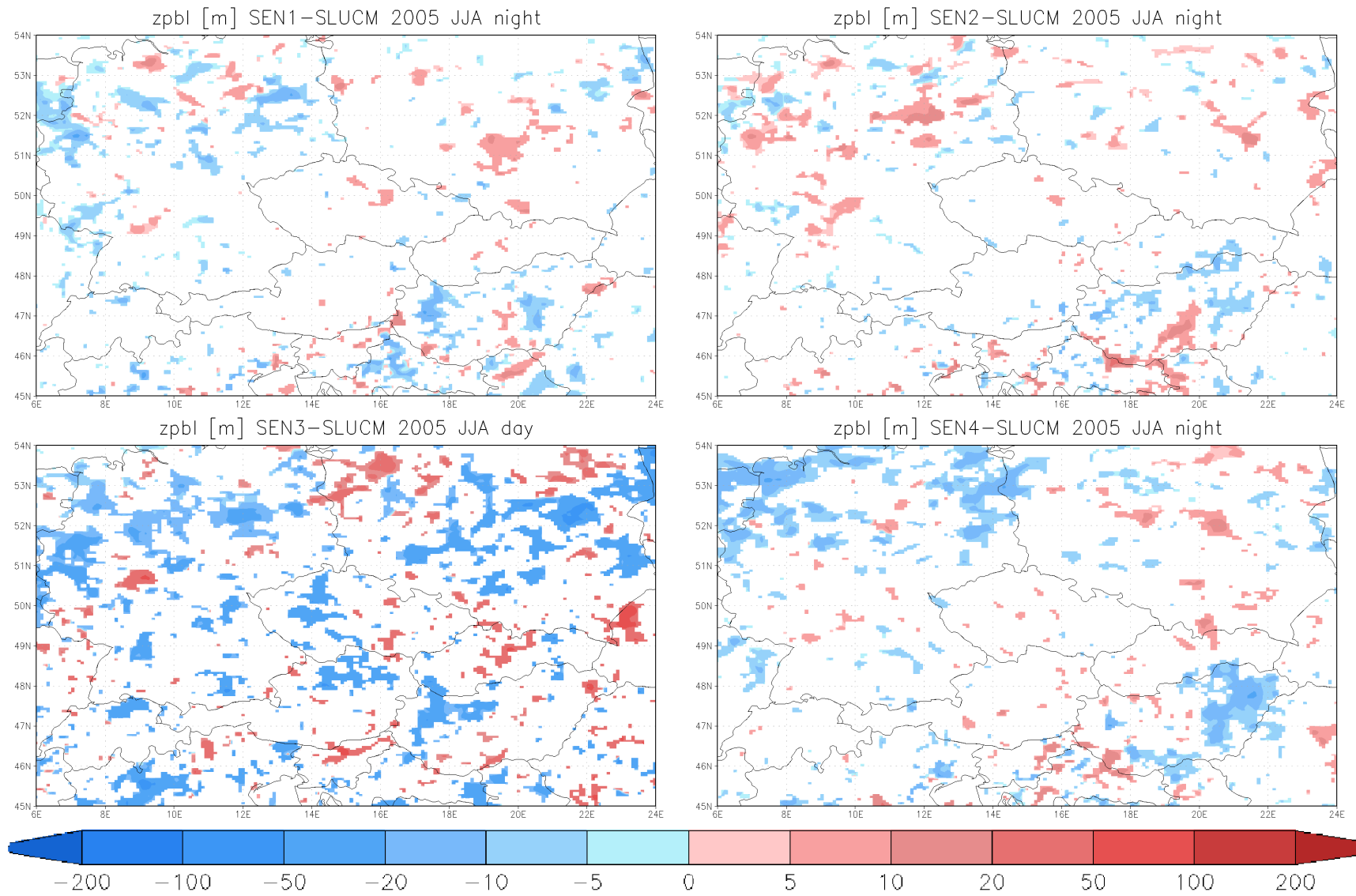

Figure 11. Same as Fig. 10 but for the PBL height in $\mathrm{m}$.

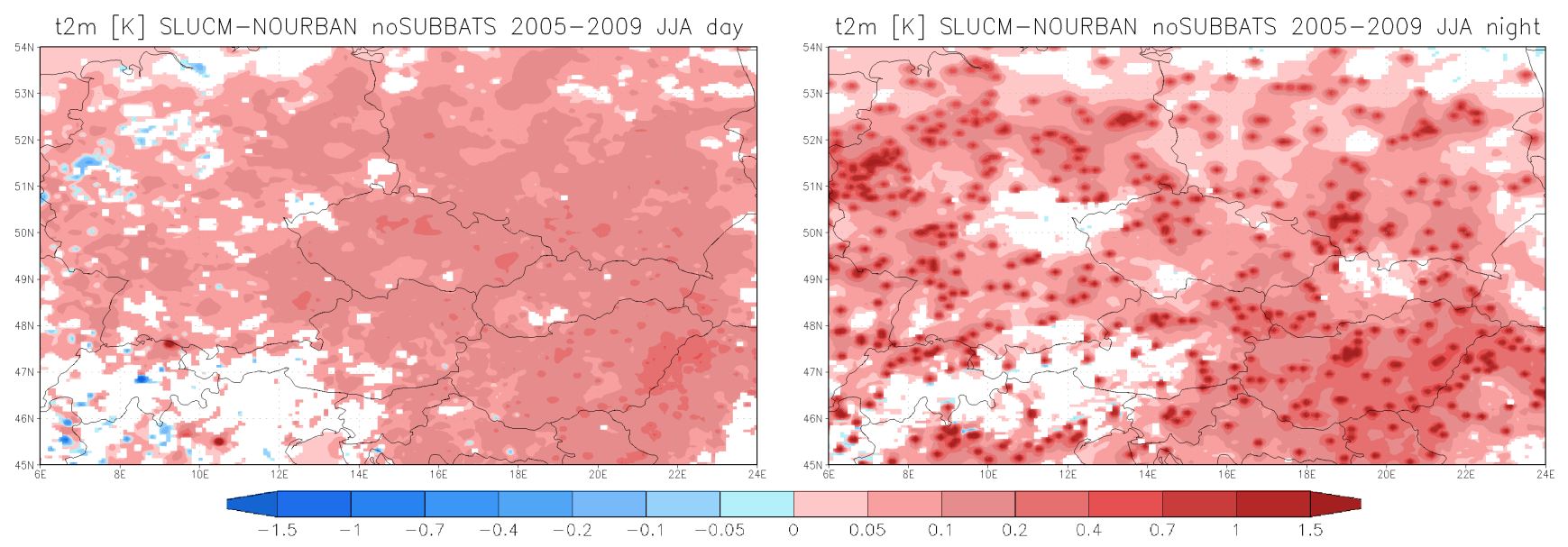

Figure 12. The impact of urbanized surfaces on the summer day (left) and night (right) near surface temperature in $\mathrm{K}$ averaged over years 2005-2009 without SUBBATS, i.e. at $10 \mathrm{~km} \times 10 \mathrm{~km}$ model resolution. Shaded areas represent statistically significant differences on the $95 \%$ level.

and night hours seen in previous studies for European cities (Eliasson and Holmer, 1990 for Gothenburg; Pichierri et al., 2012 for Milan; Giannaros and Melas, 2012 for Thessaloniki; Giannaros et al., 2013 for Athens) or for US cities (e.g. Ole- son et al., 2008). In winter, the impact is significant mainly during daytime (seen similarly in Struzewska and Kaminski (2012)), which is probably due to the governing role of AHR being stronger during the day. Indeed, the hourly profiles in 
Table 4. Sensitivity tests: changes in selected meteorological parameters $\left(T_{2} \mathrm{~m}-2 \mathrm{~m}\right.$ temperature $[\mathrm{K}], Z_{\mathrm{pbl}}-$ planetary boundary layer height [m], $V_{10 \mathrm{~m}}$ - wind speed at $10 \mathrm{~m} \mathrm{~s}^{-1}[\mathrm{~m}], Q_{2 \mathrm{~m}}-$ specific humidity at $2 \mathrm{~m}\left[\mathrm{~g} \mathrm{~kg}^{-1}\right], P_{\mathrm{tot}}-$ total precipitation rate $\left.\left[\mathrm{mm} \mathrm{day}^{-1}\right]\right)$ over five cities due to changes in urban canopy parameters of SLUCM for day and night-time in summer 2005. Bold numbers indicate statistically significant differences on the $95 \%$ level.

\begin{tabular}{|c|c|c|c|c|c|c|c|c|c|c|c|}
\hline & & \multicolumn{2}{|c|}{ Prague } & \multicolumn{2}{|c|}{ Vienna } & \multicolumn{2}{|c|}{ Budapest } & \multicolumn{2}{|c|}{ Munich } & \multicolumn{2}{|c|}{ Berlin } \\
\hline & & $\begin{array}{l}\text { JJA } \\
\text { day }\end{array}$ & $\begin{array}{r}\text { JJA } \\
\text { night }\end{array}$ & $\begin{array}{l}\text { JJA } \\
\text { day }\end{array}$ & $\begin{array}{r}\text { JJA } \\
\text { night }\end{array}$ & $\begin{array}{l}\text { JJA } \\
\text { day }\end{array}$ & $\begin{array}{r}\text { JJA } \\
\text { night }\end{array}$ & $\begin{array}{l}\text { JJA } \\
\text { day }\end{array}$ & $\begin{array}{r}\text { JJA } \\
\text { night }\end{array}$ & $\begin{array}{l}\text { JJA } \\
\text { day }\end{array}$ & $\begin{array}{r}\text { JJA } \\
\text { night }\end{array}$ \\
\hline \multirow{5}{*}{$\begin{array}{l}\text { SEN1 } \\
\text { b.height } \\
50 \%\end{array}$} & $T_{2 \mathrm{~m}}$ & -0.02 & -0.03 & -0.00 & -0.06 & 0.00 & -0.13 & -0.06 & -0.04 & 0.05 & -0.28 \\
\hline & $Z_{\mathrm{pbl}}$ & -4.52 & -1.01 & -8.83 & -1.49 & -4.12 & -1.34 & -13.5 & 0.9 & -9.57 & -18.9 \\
\hline & $V_{10 \mathrm{~m}}$ & 0.06 & -0.03 & 0.11 & 0.05 & 0.09 & -0.02 & 0.01 & 0.01 & 0.31 & 0.06 \\
\hline & $Q_{2 \mathrm{~m}}$ & 0.02 & $\mathbf{0 . 0 2}$ & 0.01 & -0.00 & -0.00 & -0.01 & 0.05 & 0.00 & 0.04 & 0.08 \\
\hline & $P_{\text {tot }}$ & 0.39 & -0.44 & -0.23 & 0.27 & -0.40 & 0.10 & 0.88 & -0.12 & 0.10 & 0.23 \\
\hline \multirow{5}{*}{$\begin{array}{l}\text { SEN2 } \\
\text { str.width } \\
50 \%\end{array}$} & $T_{2 \mathrm{~m}}$ & & 0.03 & 0.02 & 0.02 & -0.02 & 0.01 & 0.00 & 0.03 & 0.08 & 0.10 \\
\hline & $Z_{\mathrm{pbl}}$ & -0.40 & 4.35 & -13.6 & 3.47 & 4.13 & 4.67 & 4.93 & 0.84 & 7.55 & 8.73 \\
\hline & $V_{10 \mathrm{~m}}$ & 0.06 & 0.09 & 0.10 & 0.14 & 0.12 & 0.10 & 0.05 & 0.02 & 0.30 & 0.31 \\
\hline & $Q_{2 \mathrm{~m}}$ & -0.01 & -0.00 & 0.01 & -0.02 & 0.00 & -0.00 & 0.01 & 0.00 & -0.05 & -0.00 \\
\hline & $P_{\text {tot }}$ & -0.46 & -0.60 & 0.11 & -0.03 & -0.41 & 0.29 & 0.70 & -0.39 & -0.05 & -0.07 \\
\hline \multirow{5}{*}{$\begin{array}{l}\text { SEN3 } \\
2 \mathrm{x} \\
\text { roof alb. }\end{array}$} & $T_{2 \mathrm{~m}}$ & -0.11 & -0.20 & -0.11 & 0.02 & -0.06 & 0.01 & -0.08 & -0.01 & -0.13 & -0.00 \\
\hline & $Z_{\mathrm{pbl}}$ & -17.5 & 1.11 & -31.8 & 4.86 & -11.0 & 8.46 & -28.7 & 3.00 & -24.8 & -1.92 \\
\hline & $V_{10 \mathrm{~m}}$ & -0.02 & -0.03 & -0.02 & 0.02 & -0.02 & -0.01 & -0.04 & -0.01 & -0.05 & -0.00 \\
\hline & $Q_{2 \mathrm{~m}}$ & 0.02 & 0.02 & -0.01 & -0.01 & -0.05 & -0.06 & 0.03 & -0.00 & -0.00 & 0.04 \\
\hline & $P_{\text {tot }}$ & 0.17 & -1.00 & 0.10 & 0.02 & -0.57 & 0.36 & 0.56 & -0.33 & -0.05 & -0.09 \\
\hline SEN4 & $T_{2 \mathrm{~m}}$ & -0.07 & -0.01 & -0.05 & 0.03 & -0.04 & -0.05 & -0.1 & -0.04 & -0.07 & -0.10 \\
\hline AHR & $Z_{\mathrm{pbl}}$ & -15.6 & 5.38 & 8.71 & 5.63 & -6.60 & 8.57 & -37.7 & 3.15 & -17.6 & -9.14 \\
\hline \multirow[t]{3}{*}{$50 \%$} & $V_{10 \mathrm{~m}}$ & -0.02 & 0.01 & -0.02 & 0.01 & 0.03 & -0.02 & -0.03 & -0.02 & 0.01 & -0.05 \\
\hline & $Q_{2 \mathrm{~m}}$ & 0.04 & 0.02 & -0.00 & -0.00 & -0.00 & -0.02 & 0.00 & -0.02 & 0.02 & 0.09 \\
\hline & $P_{\mathrm{tot}}$ & 0.45 & -0.37 & -1.00 & -0.17 & -0.19 & 0.18 & 0.67 & -0.02 & -0.59 & 0.19 \\
\hline
\end{tabular}

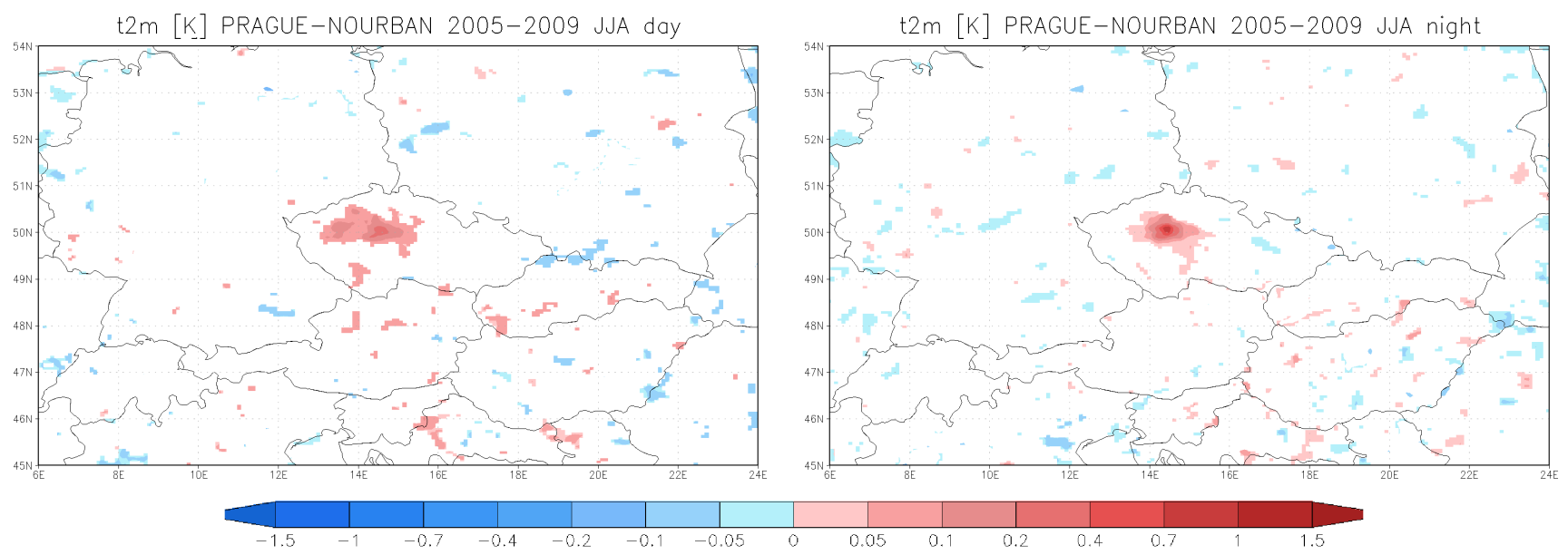

Figure 13. Impact of urbanized surfaces corresponding to Prague on the near surface temperature including the SUBBATS surface treatment $(2 \mathrm{~km} \times 2 \mathrm{~km}$ resolution). Shaded areas represent statistically significant differences on the $95 \%$ level.

our simulations assume that significantly larger heat is released from vehicular traffic during the day than during the night; and that AHR from indoor heating peaks during morning hours as the heat from nocturnal heating is released with a lag due to thermal conduction through the roofs and walls (Sailor and Lu, 2004). As a result, daytime AHR is slightly stronger than during the night. Feng et al. (2012) also found AHR to be the most important factor influencing the urban impact on winter temperatures. The night-time decrease of temperature during winter (seen especially for Berlin, Prague or Budapest) is probably the result of stabilized PBL and reduced wind speeds (see further), which can lead to development of stronger winter inversion layers.

It is also found that enhanced vertical mixing in summer causes the impact of urban surfaces on temperature to spread across the whole PBL. The modelled decrease of temperature over the PBL can be explained by the increased vertical lapse 

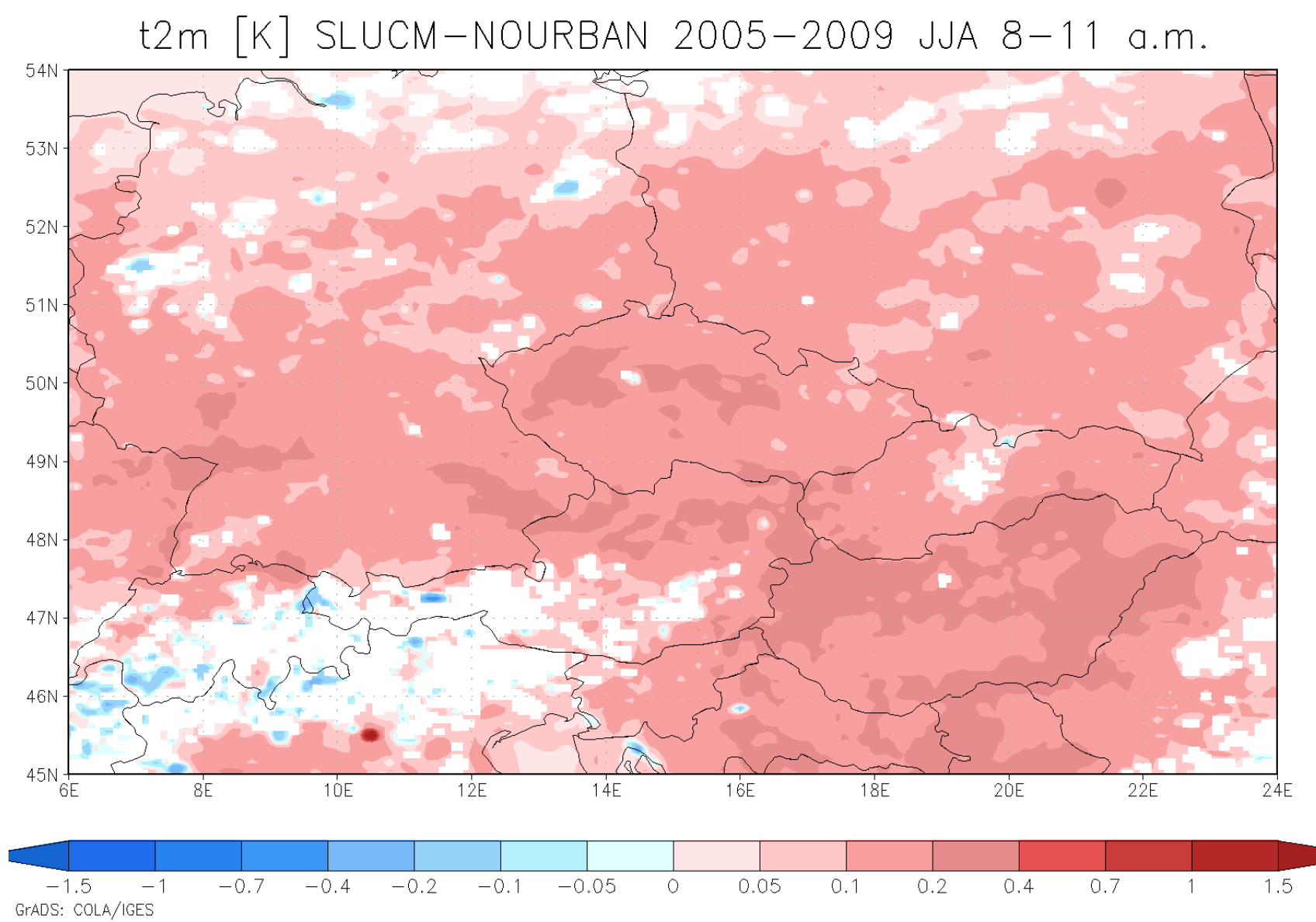

Figure 14. The cool island effect: the impact of urbanized surfaces on the summer morning 8-11 a.m. near surface temperature in K averaged over years 2005-2009. Shaded areas represent statistically significant differences on the $95 \%$ level.

rate due to higher PBL temperature, resulting in enhanced convective motion, as discussed by Collier (2006).

According to our results, the diurnal temperature range reduction due to urbanized surfaces is about $-0.8 \mathrm{~K}$ in summer and $-0.2 \mathrm{~K}$ in winter, which is lower than values found in Trusilova et al. (2008) ( -1.2 and $-0.7 \mathrm{~K}$, respectively).

In our simulations, the PBL height increases in both winter and summer daytime, and summer night-time, but decrease is modelled over cities in winter night-time. The daytime increase is explained by enhanced turbulent mixing due to the urban morphology as already found by Martilli (2002); Angevine et al. (2003); Rotach et al. (2005); Collier (2006). The summer night-time PBL increase is limited over cities and can be the result of warmer air in the nocturnal PBL due to UHI. In winter night-time, a slight PBL height reduction is modelled. This is attributable to decreased wind speeds (see below), which leads to decreased mixing.

The wind speed changes in both winter and summer daytime are characterized with a slight decrease over cities. Similar decreases were found by Klaić et al. (2002). Hou et al. (2013) attributed this wind stilling to increased surface roughness. A similar conclusion was made by Vautard et al. (2010) analysing the observed Northern Hemispheric wind stilling. Another factor influencing the urbanization impact on wind is the destabilization of urban boundary layer (UBL) due to higher urban temperatures (seen also in connection with the PBL increase), which on the other hand leads to enhanced winds. These competing effects may result in slight wind speed decrease over cities and a small wind speed increase around these areas during daytime.

The increase in wind speed during night-time can be related to decreased nocturnal stability due to the presence of UHI. Another contributing factor could be the generation of urban-breeze circulation, i.e. formation of convergent motions towards the city as a result of thermally induced horizontal pressure gradient (Hidalgo et al., 2010), however, it is probably not resolvable with our dynamical $10 \mathrm{~km} \times 10$ $\mathrm{km}$ resolution. Indeed, most of the studies dealing with this type of circulation used much finer horizontal step, e.g. the mentioned study calculated on a $500 \mathrm{~m} \times 500 \mathrm{~m}$ grid.

Enhanced roughness in urban environment may play a governing factor in the winter night-time decrease of winds, 
resulting in lower modelled PBL heights, which was also documented by Hou et al. (2013). A different summer nocturnal behaviour is simulated for northern Italy (urban areas within the Po valley). Here, even in summer night-time, wind speed decrease is modelled, again, probably governed by increased surface drag. A similar result was recently found for another mediterranean city, Lisbon (Portugal) by Lopes et al. (2012).

Apart from no significant changes in winter precipitation (which we do not present in this study), our results show very small impact on also the night summer precipitation. However, a statistically significant decrease of rainfall is modelled in summer during daytime. Compared to Trusilova et al. (2008), our results indicate a slightly stronger precipitation reduction: up to $20-30 \%$ for summer precipitation (even stronger, $50 \%$ reduction in summer daytime) compared to about $20 \%$ reduction found in the mentioned study. This decrease was mostly driven by the convective precipitation the large scale precipitation was not perturbed statistically significantly in our simulations. There has been evidence in other studies (e.g. Kaufmann et al., 2007) that within urban environment, the rain formation is suppressed, due to decreased availability of moisture. Indeed, our results suggest significant reduction of specific humidity in the whole PBL over large areas not limited only to urban centres. The Grell convective scheme (Grell, 1993) with the Fritsch and Chappell closure (Fritsch and Chappell, 1980) used in this study considers that the precipitation rate is proportional to the updraft mass flux, which is further proportional to the buoyant energy available for convection (ABE). With higher lapse rate the $\mathrm{ABE}$ increases but the lower humidity in the PBL is counteracting and suppresses ABE. In our simulations, this latter effect dominates. In summary, even with potentially stronger vertical convective motion caused by increased temperature lapse rate, less available moisture leads to reduced precipitation formation in the end. Similar results and conclusions are drawn in Trusilova et al. (2008) for their CENTER_EU region, which largely overlaps with our domain.

Enhancement of precipitation downwind of urban areas was documented by several measurement or model studies (Shepherd et al., 2002; Jauregui, 1991; Changon et al., 1991; Rozoff et al., 2003). This enhancement is seen in our results only around a few cities, but in most of the cases they are not statistically significant. The comparison is however problematic, as already pointed out by Trusilova et al. (2008): the mentioned studies focused on tropical climate and furthermore, they compared the downwind with the upwind precipitation of the city, while we compared the rainfall corresponding to the present state of urbanization with a hypothetical state with no urban coverage, i.e. two different states of atmospheric circulation.

The comparison of monthly temperature data over cities with measurements reveals a negative model bias in summer months, which is probably due to overestimation of cloudi- ness in our simulations. However, after applying the SLUCM urban canopy treatment, the negative bias in summer is reduced or, in some cases, vanishes entirely. Improvement in model performance is evident from the comparison of diurnal temperature variation with observed temperatures as well. The negative model bias is significantly reduced during afternoon and evening hours when the urban meteorological effects are most prominent.

It is important to emphasize that, regarding the temperature, the impact of urban surfaces is not identical to the UHI magnitude, as the UHI is defined as the temperature difference between the city centre and its urban effect-free vicinity. We demonstrated in our simulations that the cities impact temperatures over rural areas as well. Hence, the reference state corresponding to the absence of urban surfaces (the NOURBAN experiment) is colder than the reference for the UHI magnitude calculation at a particular city. This was well seen in the plots showing the hourly temperature variation over selected cities where the temperatures in the city's vicinity are higher than if there were no cities at all. Then, the annual mean UHI magnitude is $0.5-1 \mathrm{~K}$. Unger et al. (2011) provide information on the annual mean UHI from a middle sized central European city of Novi Sad in Serbia and they find UHI up to $4 \mathrm{~K}$. However, this value is representative of the very centre of the city of a few square kilometres, while in our simulations we averaged the temperature from a $10 \mathrm{~km} \times 10 \mathrm{~km}$ grid box. If the UHI values from the aforementioned study are averaged over such an area around the city centre, the values decrease to $1-2 \mathrm{~K}$, which is closer to our results. The same is true for Bottyan and Unger (2003) who provide mean maximum UHI intensity of 2.1 and $3.1 \mathrm{~K}$ for the Hungarian city of Szeged during heating and nonheating season, respectively. Based on satellite data, Pongrácz et al. (2010) found the 2001-2003 mean night-time UHI values in central European cities to be around $2 \mathrm{~K}$. They defined the city as a $15 \mathrm{~km}$ radius circle around the centre and a $15-25 \mathrm{~km}$ belt around represented the rural areas for determining the UHI. This corresponds well to our definition and suggests an underestimation of UHI in our simulations. A more pronounced UHI was also simulated by Fallmann et al. (2013) for Stuttgart (around 2.5 K, compared to our value of about $0.7 \mathrm{~K}$ ). They, however, used a much finer resolution of $1 \mathrm{~km} \times 1 \mathrm{~km}$ and the city averaged UHI intensity $(1.3 \mathrm{~K})$, which is a more comparable quantity with our values, is again closer to our result. It should be noted that their experiments were carried out for an exceptionally warm period from 11 to 18 August during the 2003 heat wave, while we averaged over summers from 5 years.

The measured data over Prague revealed the UCI effect as well, which was also reproduced by the model, but to a much lesser extent. Fig. 14, illustrating the spatial distribution of the morning temperature response to urban coverage, shows an overall warming already seen during both night and daytime conditions but also indicates a cooling for larger cities, especially over the western part of the domain. The re- 
sults suggest presence of the UCI effect also for other cities. However, the cooling is usually eliminated by counteracting warming seen all over the domain. Therefore the results are either insignificant (Munich, Budapest) or the they show only a reduction of temperature impact (Brno - Czech Republic, Poznan - Poland).

The sensitivity analysis for the summer meteorological conditions showed a rather limited dependence on the model setup of the geometric and radiative characteristics of the urban environment. Specifically, the temperature responses to significant changes of geometry parameters such as street width or building height are of the order $0.01 \mathrm{~K}$ (up to $0.1 \mathrm{~K}$ in a few cases). The same is true for the AHR. Somewhat stronger temperature response was detected for the building roof albedo value. The changes of the boundary layer height can be as high as a few tens of metres when perturbing the key SLUCM parameters in our simulations, which is closer to the average modelled ZPBL change (Fig. 4) and reveals relatively large sensitivity of ZPBL to urban parameters. Similarly, a substantial dependence of the $10 \mathrm{~m}$ wind velocity on the urban geometry parameters is modelled (with changes in the order of $0.1 \mathrm{~m} \mathrm{~s}^{-1}$ ), which is comparable to the absolute impact of urban surfaces. The roof albedo and the AHR had a very little impact on the wind speed. The dependence of the impact on the humidity is small, but often statistically significant, especially when reducing the AHR. Finally, precipitation can be impacted largely when changing the SLUCM parameters (up to $-1 \mathrm{~mm} \mathrm{day}^{-1}$ when reducing AHR), but these changes are usually insignificant in a statistical sense. Therefore, it can be concluded that the results concerning the impact of urbanized surfaces on the long-term meteorological conditions over central Europe are, with respect to the overall uncertainty of parameters settings, quite robust. Efforts aiming to set the urban parameters more precisely with the eventuality of using 2-D distribution of these parameters will change the overall picture probably only a little.

Another important conclusion regarding the impact of urban surfaces on temperature is that in central Europe it is not limited to large cities only, but can be significant over remote areas with rather minor urban development as well. A question arises whether this impact is the result of the presence of smaller cities, i.e. a few urbanized subgrid boxes in the corresponding $10 \mathrm{~km} \times 10 \mathrm{~km}$ grid boxes, or whether urban surfaces have distant influence on non-urbanized areas far from them. Figure 2 (right) shows that at $2 \mathrm{~km} \times 2 \mathrm{~km}$ resolution, the domain is densely populated by urban surfaces and, actually, most of the corresponding $10 \mathrm{~km} \times 10 \mathrm{~km}$ grid boxes really contain at least a few urban subgrid boxes. These might contribute to the impact on the whole grid box depending roughly on the percent urban coverage of the grid box. Indeed, Fig. 12 shows that if using only the $10 \mathrm{~km} \times 10 \mathrm{~km}$ resolution, the temperature impact is significantly larger over these grid boxes than elsewhere. On the other hand, there is still a relatively large impact over non-urbanized grid boxes that can reach $0.2 \mathrm{~K}$, and which could be attributed to the remote impact of UHI. However, Fig. 3 shows that for nighttime conditions over areas with minor urbanization, such impact is slightly higher (by $0.05 \mathrm{~K}$ ). This indicates that these small urban elements (smaller cities, suburban and partly urbanized areas) can contribute to the impact. This conclusion could partially affect, at least in the areas with highly populated urbanized areas as in Europe, the temperature increase under global warming, supposing the rapid development of the urbanization in the region.

The second question relates to the remoteness of the urban impact, i.e. how purely rural areas can be influenced by nearby (or even more distant) cities. In Fig. 13, the impact of Prague is apparently limited to the surrounding region of no more than $150 \mathrm{~km}$ diameter, elsewhere the impact is statistically insignificant (except a little noise which has not been eliminated using 5 years long simulations and $95 \%$ significance threshold). In conclusion, it can be summarized that over remote areas the modelled temperature impact is a combination of the distant impact of surrounding large urbanized areas and the local impact of the few small urbanized subgrid-boxes located in the corresponding grid box. The remote impact is probably caused by the advection of warm air originating from UHI over non-urbanized areas. This is well observed especially during daytime (in summer), when wind speed is higher, resulting in smooth, almost uniform urban impact on temperature across the domain. Feng et al. (2012) simulated the long-term regional impact of urbanization and AHR and found values similar to our study: over most of the eastern China exceeding $1 \mathrm{~K}$ for the summer average.

The question remains what improvement of the results can be achieved by using a more sophisticated urban canopy model, such as the multilayer BEP (Building Energy Parameterization) model (Martilli et al., 2002). It will certainly better describe the 3-D nature of the heat, moisture and momentum exchange between buildings and street-canyon, impacting the thermodynamic structure of the urban roughness sublayer and hence the lower part of the urban boundary layer. Although a multi-layer urban canopy model represents an increase of computational demand compared to SLUCM, future work should focus in this direction and apply such models in long-term climate simulations in combination with regional climate models, in order to obtain a more accurate picture about the climatic impact of urbanization on a regional scale.

The results obtained in this study have implications in atmospheric chemistry as well. As the chemical transformation, transport, diffusion and deposition of chemical species and aerosols are strongly linked to the meteorological (thus climate) conditions, the urban canopy induced changes calculated here may, in general, have impact on the air quality as well. This was a subject of a few studies focusing on London and Seoul (Rigby and Toumi, 2008; Ryu et al., 2013a, b). A future study will deal with the potential consequences on the air quality over central Europe as well. 
Acknowledgements. This work has been funded by the Czech Science Foundation (GACR) project no. 13-19733P as well as by the project UHI funded in the framework of EC OP NN (no. 3CE292P3), the program PRVOUK - Environmental Research of the Charles University in Prague and, partially, by the project UNCE 204020/2013. We further acknowledge the E-OBS data set from the EU-FP6 project ENSEMBLES (http://ensembles-eu.metoffice.com), the data providers in the ECA\&D project (http://www.ecad.eu) and finally to ECMWF ERA/Interim data sets.

Edited by: A. Hofzumahaus

\section{References}

Angevine, W. M., White, A. B., Senff, C. J., Trainer, M., Banta, R. M., and Ayoub, M. A.: Urban-rural contrasts in mixing height and cloudiness over Nashville in 1999, J. Geophys. Res., 108, 4092, doi:10.1029/2001JD001061, 2003.

Anthes, R. A.: A cumulus parameterization scheme utilizing a onedimensional cloud model, Mon. Weather Rev., 105, 270-286, 1977.

Baklanov, A., Korsholm, U., Mahura, A., Petersen, C., and Gross, A.: ENVIRO-HIRLAM: on-line coupled modelling of urban meteorology and air pollution, Adv. Sci. Res., 2, 41-46, doi:10.5194/asr-2-41-2008, 2008.

Basara, J. B., Hall Jr., P. K., Schroeder, A. J., Illston, B. G., and Nemunaitis, K. L.: Diurnal cycle of the Oklahoma City urban heat island, J. Geophys. Res., 113, D20109, doi:10.1029/2008JD010311, 2008.

Block, A., Keuler, K., and Schaller, E.: Impacts of anthropogenic heat on regional climate patterns, Geophys. Res. Lett., 31, L12211, doi:10.1029/2004GL019852, 2004

Bottyan, Z. and Unger, J.: A multiple linear statistical model for estimating the mean maximum urban heat island, Theor. Appl. Climatol., 75, 233-243, 2003.

Changnon, S. A., Shealy, R. T., and Scott, R. W.: Precipitation Changes in Fall, Winter, and Spring Caused by St. Louis, J. Appl. Meteorol., 30, 126-134, 1991.

Chen, F., Kusaka, H., Bornstein, R., Ching, J., Grimmond, C. S. B., Grossman-Clarke, S., Loridan, T., Manning, K. W., Martilli, A., Miao, S., Sailor, D., Salamanca, F. P., Taha, H., Tewari, M., Wang, X., Wyszogrodzki, A. A., and Zhang, C.: The integrated WRF/urban modelling system: development, evaluation, and applications to urban environmental problems, Int. J. Climatol., 31, 273-288, 2011.

Cleugh, H. A. and Grimmond, C. S. B.: Modelling regional scale surface energy exchanges and CBL growth in a heterogeneous, urbanrural landscape, Bound.-Lay. Meteorol., 98, 1-31, 2001.

Collier, C. G.: The impact of urban areas on weather, Q. J. Roy. Meteor. Soc., 132, 1-25, 2006.

Coquillat, S., Boussaton, M.-P., Buguet, M., Lambert, D., Ribaud, J.-F., and Berthelot, A.: Lightning ground flash patterns over Paris area between 1992 and 2003: influence of pollution?, Atmos. Res., 122, 77-92, doi:10.1016/j.atmosres.2012.10.032, 2013.
Deardoff, J. W.: Efficient prediction of ground surface temperature and moisture with inclusion of a layer of vegetation, J. Geophys. Res., 83, 1889-1903, 1978.

Dettwiller, J. and Changnon, S. A.: Possible urban effects on maximum daily rainfall at Paris, St. Louis and Chicago, J. Appl. Meteorol., 15, 518-519, 1976.

Dickinson, R. E., Henderson-Sellers, A., and Kennedy, P.: Biosphere-atmosphere transfer scheme (BATS) version 1 as coupled to the NCAR community climate model. Tech Rep, National Center for Atmospheric Research Tech Note NCA R.TN387+STR, NCAR, Boulder, CO, 1993.

EEA: Corine Land Cover 2006 technical guidelines, EEA (European Environment Agency), OPOCE (Office for Official Publications of the European Communities), Copenhagen, 2012.

Eliasson, I. and Holmer, B.: Urban heat island circulation in Goteborg, Sweden, Theor. Appl. Climatol., 42, 187-196, 1990.

Emanuel, K. A. and M. Zivkovic-Rothman, M.: Development and evaluation of a convection scheme for use in climate models, $\mathrm{J}$. Atmos. Sci., 56, 1766-1782, 1999.

Fallmann, J., Emeis, S., and Suppan, P.: Mitigation of urban heat stress - a modelling case study for the area of Stuttgart, Die Erde, 144, 202-216, doi:10.12854/erde-144-15, 2013.

Farias, W. R. G., Pinto Jr., O., Naccarato, K. P., and Pinto, I. R. C. A.: Anomalous lightning activity over the Metropolitan Region of São Paulo due to urban effects, Atmos. Res., 91, 485-490, 2009.

Feng, J.-M., Wang, Y.-L., Ma, Z.-G., and Liu, Y.-H.: Simulating the regional impacts of urbanization and anthropogenic heat release on climate across china, J. Climate, 25, 7187-7203, doi:10.1175/JCLI-D-11-00333.1, 2012.

Feng, J.-M., Wang, Y.-L., and Ma, Z.-G.: Long-term simulation of large-scale urbanization effect on the East Asian monsoon, Clim. Change, 1-13, doi:10.1007/s10584-013-0885-2, 2013.

Flagg, D. D. and Taylor, P. A.: Sensitivity of mesoscale model urban boundary layer meteorology to the scale of urban representation, Atmos. Chem. Phys., 11, 2951-2972, doi:10.5194/acp-11-29512011, 2011.

Fritsch, J. M. and Chappell, C. F.: Numerical prediction of convectively driven mesoscale pressure systems, Part I: Convective parameterization, J. Atmos. Sci., 37, 1722-1733, 1980.

Gaffin, S. R., Rosenzweig, C., Khanbilvardi, R., Parshall, L., Mahani, S., Glickman, H., Goldberg, R., Blake, R., Slosberg, R. B., and Hillel, D.: Variations in New York City's urban heat island strength over time and space, Theor. Appl. Climatol., 94, 1-11, doi:10.1007/s00704-007-0368-3, 2008.

Giannaros, T. M. and Melas, D.: Study of the urban heat island in a coastal Mediterranean city: the case study of Thessaloniki, Greece, Atmos. Res., 118, 103-120, doi:10.1016/j.atmosres.2012.06.006, 2012.

Giannaros, T. M., Melas, D., Daglis, I. A., Keramitsoglou, I., and Kourtidis, K.: Numerical study of the urban heat island over Athens (Greece) with the WRF model, Atmos. Environ., 73, 103-111, doi:10.1016/j.atmosenv.2013.02.055, 2013.

Giorgi, F., Francisco, R., and Pal, J. S.: Effects of a sub-grid scale topography and landuse scheme on surface climate and hydrology. I. Effects of temperature and water vapor disaggregation, J. Hydrometeorol., 4, 317-333, 200

Giorgi, F., Coppola, E., Solmon, F., Mariotti, L., Sylla, M., Bi, X., Elguindi, N., Diro, G. T., Nair, V., Giuliani, G., Cozzini, S., Guet- 
tler, I., O’Brien, T. A., Tawfi, A. B., Shalaby, A., Zakey, A., Steiner, A., Stordal, F., Sloan, L., and Brankovic, C.: RegCM4: Model description and preliminary tests over multiple CORDEX domains, Clim. Res., 52, 7-29, 2012.

GLC: Global Land Cover 2000 database. European Commission, Joint Research Centre, available at: http://bioval.jrc.ec.europa. eu/products/glc2000/glc2000.php (last access: 14 July 2014), 2000.

Godowitch, J. M., Ching, J. K. S., and Clarke, J. F.: Evolution of the nocturnal inversion layer at an urban and nonurban site, J. Appl. Meteorol. Clim., 24, 791-804, 1985.

Grell, G.: Prognostic evaluation of assumptions used by cumulus parameterizations, Mon. Weather Rev., 121, 764-787, 1993.

Grell, G., Dudhia, J., and Stauffer, D. R.: A description of the fifth generation Penn State/NCAR Mesoscale Model (MM5), National Center for Atmospheric Research Tech Note NCAR/TN398 + STR, NCAR, Boulder, CO, 1994.

Grimmond, C. S. B. and Oke, T.: An evapotranspirationinterception model for urban areas, Wafer Resour. Res. 27, 1739, doi:10.1029/91WR00557, 1991.

Grimmond, C. S. B. and Oke, T. R.: Comparison of heat fluxes from summertime observations in the suburbs of four North American cities. J. Appl. Meteorol., 34, 873-889, 1995

Grimmond, C. S. B. and Oke, T. R.: Turbulent heat fluxes in urban areas: Observations and a local-scale urban meteorological parameterization scheme (LUMPS), J. Appl. Meteorol., 41, 792-810, 2002.

Haeger-Eugensson, M. and Holmer, B.: Advection caused by the UHIC as a regulating factor on the nocturnal UHI, Int. J. Climatol., 19, 975-988, 1999.

Haylock, M. R., Hofstra, N., Klein Tank, A. M. G., Klok, E. J., Jones, P. D., and New, M.: A European daily high-resolution gridded dataset of surface temperature and precipitation. J. Geophys. Res.-Atmos., 113, D20119, doi:10.1029/2008JD010201, 2008.

Hidalgo, J., Masson, V., and Gimeno, L.: Scaling the Daytime Urban Heat Island and Urban-Breeze Circulation, J. Appl. Meteorol. Clim., 49, 889-901, 2010.

Holtslag, A. A. M., Bruijn, E. I. F. D., and Pan, H.-L.: A high resolution air mass transformation model for short-range weather forecasting, Mon. Weather Rev., 118, 1561-1575, 1990.

Hou, A., Ni, G., Yang, H., and Lei, Z.: Numerical Analysis on the Contribution of Urbanization to Wind Stilling: an Example over the Greater Beijing Metropolitan Area, J. Appl. Meteorol. Clim., 52, 1105-1115, doi:10.1175/JAMC-D-12-013.1, 2013.

Jauregui, E.: Influence of a large urban park on temperature and convective precipitation in a tropical city, Energ. Buildings, 15, 457-463, 1991.

Kastner-Klein, P., Fedorovich, E., and Rotach, M. W.: A wind tunnel study of organised and turbulent air motions in urban street canyons, J. Wind Eng. Ind. Aerod., 89, 849-861, 2001.

Kaufmann, R. K., Seto, K. C., Schneider, A., Liu, Z., Zhou, L., and Wang, W.: Climate response to rapid urban growth: evidence of a human-induced precipitation deficit, J. Climate, 20, 2299-2306, 2007.

Kiehl, J., Hack, J., Bonan, G., Boville, B., Breigleb, B., Williamson, D., and Rasch, P.: Description of the NCAR Community Climate Model (CCM3). National Center for Atmo- spheric Research Tech Note NCAR/TN-420+STR, NCAR, Boulder, CO, 1996.

Klaić, Z. B., Nitis, T., Kos, I., and Moussiopoulos, N.: Modification of local winds due to hypothetical urbanization of the Zagreb surroundings, Meteorol. Atmos. Phys., 79, 1-12, 2002.

Kłysik, K.: Spatial and seasonal distribution of anthropogenic heat emissions in Åodz, Poland, Atmos. Environ., 30, 3397-3404, 1995.

Kueppers, L. M., Snyder, M. A., Sloan, L. C., Cayan, D., Jin, J., Kanamaru, H., Kanamitsu, M., Miller, N. L., Tyree, M., Du, H., and Weare, B.: Seasonal temperature response to land-use change in the western United States, Global Planet. Change, 60, 250-264, 2008.

Kusaka, H. and Kimura, F.: Coupling a single-layer urban canopy model with a simple atmospheric model: impact on urban heat island simulation for an idealized case, J. Meteorol. Soc. Jpn., 82, 67-80, 2004.

Kusaka, H., Kondo, H., Kikegawa, Y., and Kimura, F.: A simple singlelayer urban canopy model for atmospheric models: comparison with multi-layer and slab models, Bound.-Lay. Meteorol., 101, 329-358, 2001.

Lee, S.-H. and Park, S.-U.: A vegetated urban canopy model for meteorological and environmental modelling, Bound.-Lay. Meteorol., 126, 73-102, 2008.

Lopes, A., Saraiva, J., and Alcoforado, M. J.: Urban boundary layer wind speed reduction in summer due to urban growth and environmental consequences in Lisbon, Environ. Modell. Softw., 54, 611-623, doi:10.1016/j.atmosenv.2012.02.024, 2012.

Masson, V.: A physically-based scheme for the urban energy budget in atmospheric models, Bound.-Lay. Meteorol., 94, 357-397, 2000.

Martilli, A: Numerical study of urban impact on boundary layer structure: sensitivity to wind speed, urban morphology, and rural soil moisture, J. Appl. Meteorol., 41, 1247-1266, 2002.

Martilli, A., Clappier, A., and Rotach, M. W.: An urban surface exchange parameterization for mesoscale models, Bound.-Lay. Meteorol., 104, 261-304, 2002.

Miao, S., Chen, F., LeMone, A. M., Tewari, M., Li, Q., and Wang, Y., 2009: An observational and modelling study of characteristics of urban heat island and boundary layer structures in Beijing, J. Appl. Meteorol. Clim., 48, 484-501, 2009.

Nair, K. N., Freitas, E. D., Sanchez-Ccoyllo, O. R., Dias, M., Dias, P. L. S., Andrade, M. F., and Massambani, O.: Dynamics of urban boundary layer over Sao Paulo associated with mesoscale processes, Meteorol. Atmos. Phys., 86, 87-98, 2004.

Oke, T. R.: The energetic basis of the urban heat island, Q. J. Roy. Meteor. Soc., 108, 1-24, doi:10.1002/qj.49710845502, 1982.

Oke, T. R.: Boundary Layer Climates, Methuen and Co. Ltd, London, 2nd Edn., 1987.

Oleson, K. W., Bonan, J. B., Feddema, J., Vertenstein, M., and Grimmond, C. S. B.: An urban parameterization for a global climate model, Part I: Formulation and evaluation of two cities, J. Appl. Meteorol. Clim., 47, 1038-1060, 2008.

Pal, J. S., Small, E. E., and Eltahir, E. A. B.: Simulation of regionalscale water and energy budgets: Representation of subgrid cloud and precipitation processes within RegCM, J. Geophys. Res.Atmos., 105, 29579-29594, 2000.

Pichierri, M., Bonafoni, S., and Biondi, R.: Satellite air temperature estimation for monitoring the canopy layer heat 
island of Milan, Remote Sens. Environ., 127, 130-138, doi:10.1016/j.rse.2012.08.025, 2012.

Pigeon, G., Legain, D., Durand, P., and Masson, V.: Anthropogenic heat release in an old European agglomeration (Toulouse, France), Int. J. Climatol., 27, 1969-1981, 2007.

Piringer, M.: Exploring the urban boundary layer by sodar and tethersonde, Phys. Chem. Earth Pt. B., 26, 881-885, 2001.

Pongrácz, R., Bartholy, J., and Dezső, Z.: Application of remotely sensed thermal information to urban climatology of Central European cities, Phys. Chem. Earth, 35, 95-99, doi:10.1016/j.pce.2010.03.004, 2010.

Ratti, C., Di Sabatino, S., Britte, R., Brown, M., Caton, F., and Burian, S.: Analysis of 3-D urban databases with respect to pollution dispersion for a number of European and American cities, Water Air Soil Poll., 2, 459-469, 2001.

Reid, C. E., O’Neill, M. S., Gronlund, C. J., Brines, S. J., Brown, D. G., Diez-Roux, A. V., and Schwartz, J.: Mapping community determinants of heat vulnerability, Environ. Health Persp., 117, 1730-1736, doi:10.1289/ehp.0900683, 2009.

Richards, K.: Observation and simulation of dew in rural and urban environments, Prog. Phys. Geog., 28, 76-94, 2004.

Richards, K. and Oke, T. R.: Validation and results of a scale model of dew deposition in urban environments, Int. J. Climatol., 22, 1915-1933, 2002.

Rigby, M. and Toumi, R.: London air pollution climatology: indirect evidence for urban boundary layer height and wind speed enhancement, Atmos. Environ., 42, 4932-4947, doi:10.1016/j.atmosenv.2008.02.031, 2008.

Rotach, M. W., Richner, H., Vogt, R., Christen, A., Parlow, E., Bernhofer, C., Batchvarova, E., Clappier, A., Roulet, Y.-A., Feddersen, B., Schatzmann, M., Batchvarova, E., Gryning, S.E., Mayer, H., Martucci, G., Mitev, V., Oke, T. R., Roth, M., Ruffieux, D., Salmond, J. A., and Voogt, J. A.: BUBBLE-an urban boundary layer project, Theor. Appl. Climatol., 81, 231-261, 2005.

Roth, M.: Review of atmospheric turbulence over cities, Q. J. Roy. Meteor. Soc., 126, 941-990, 2000.

Rozoff, C. M., Cotton, W. R., and Adegoke, J. O.: Simulation of St. Louis, Missouri, land use impacts on thunderstorms, J. Appl. Meteorol., 42, 716-738, 2003.

Ryu, Y.-H., Baik, J.-J., Kwak, K.-H., Kim, S., and Moon, N.: Impacts of urban land-surface forcing on ozone air quality in the Seoul metropolitan area, Atmos. Chem. Phys., 13, 2177-2194, doi:10.5194/acp-13-2177-2013, 2013a.

Ryu, Y.-H., Baik, J.-J., and Lee, S.-H.: Effects of anthropogenic heat on ozone air quality in a megacity, Atmos. Environ., 80, 20-30, doi:10.1016/j.atmosenv.2013.07.053, 2013b.

Sailor, D. J. and Lu, L.: A top-down methodology for developing diurnal and seasonal anthropogenic heating profiles for urban areas, Atmos. Environ., 38, 2737-2748, 2004.

Schaldach, R. and Alcamo, J.: Simulating the effects of urbanization, afforestation and cropland abandonment on a regional carbon balance: a case study for Central Germany, Reg. Environ. Change, 7, 137-148, doi:10.1007/s10113-007-0034-4, 2007.

Shepherd, J. M., Pierce, H., and Negri, A. J.: Rainfall modification by major urban areas: observations from spaceborne rain radar on the TRMM satellite, J. Appl. Meteorol., 41, 689-701, 2002.
Simmons, A., Uppala, S., Dee, D., and Kobayashi, S.: ERAInterim: New ECMWF Reanalysis Products from 1989 Onwards, Newsletter 110, Winter 2006/07, ECMWF, Reading, 2007.

Skamarock, W. C., Klemp, J. B., Dudhia, J., Gill, D. O., Barker, D. M., Duda, M., Huang, X.-Y., Wang, W., and Powers, J. G.: A Description of the Advanced Research WRF Version 3 NCAR Technical Note, National Center for Atmospheric Research, Boulder CO, USA, doi:10.5065/D68S4MVH, 2008.

Struzewska, J. and Kaminski, J. W.: Impact of urban parameterization on high resolution air quality forecast with the GEM - AQ model, Atmos. Chem. Phys., 12, 10387-10404, doi:10.5194/acp12-10387-2012, 2012.

Svoma, B. M. and Brazel, A.: Urban effects on the diurnal temperature cycle in Phoenix, Arizona, Clim. Res., 41, 21-29, 2010.

Taha, H.: Urban climates and heat islands: Albedo, evapotranspiration, and anthropogenic heat, Energy. Buildings, 2, 99-103, 1997.

Tanaka, S., Takeda, H., Adachi, T., and Tsuchiya, T.: Architectural Environmental Engineering, Inoue Co., Ltd., Tokyo, 301 pp., 2013 (in Japanese).

Tawfik, A. B. and Steiner, A. L.: The role of soil ice in land-atmosphere coupling over the United States: a soil moisture precipitation winter feedback mechanism. J. Geophys. Res., 116, D02113, doi:10.1029/2010JD014333, 2011.

Trusilova, K., Jung, M., Churkina, G., Karstens, U., Heimann, M., and Claussen, M.: Urbanization Impacts on the Climate in Europe: Numerical Experiments by the PSU-NCAR Mesoscale Model (MM5), J. Appl. Meteorol. Clim., 47, 1442-1455, doi:10.1175/2007JAMC1624.1, 2008.

Unger, J., Savić, S., and Gál, T.: Modelling of the annual mean urban heat island pattern for planning of representative urban climate station network, Adv. Meteorol., 2011, ID398613, doi:10.1155/2011/398613, 2011.

Vautard, R., Cattiaux, J., Yiou, P., Thepaut, J., and Ciais, P.: Northern Hemisphere atmospheric stilling partly attributed to an increase in surface roughness, Nat. Geosci., 3, 756-761, doi:10.1038/NGEO979, 2010.

Wang, J., Feng, J., Yan, Z., Hu, Y., and Jia, G.: Nested highresolution modeling of the impact of urbanization on regional climate in three vast urban agglomerations in China, J. Geophys. Res., 117, D21103, doi:10.1029/2012JD018226, 2012.

Wouters, H., De Ridder, K., Demuzere, M., Lauwaet, D., and van Lipzig, N. P. M.: The diurnal evolution of the urban heat island of Paris: a model-based case study during Summer 2006, Atmos. Chem. Phys., 13, 8525-8541, doi:10.5194/acp-13-85252013, 2013.

Yang, X., Hou, Y., and Chen, B.: Observed surface warming induced by urbanization in east China, J. Geophys. Res., 116, D14113, doi:10.1029/2010JD015452, 2011.

Zhang, H., Gao, X., and Li, Y.: Climate impacts of land-use change in China and its uncertainty in a global model simulation, Clim. Dynam., 32, 473-494, 2009.

Zhou, Y. and Ren, G.: Change in extreme temperature event frequency over mainland China, 1961-2008, Clim. Res., 50, 125-139, 2011. 